Article

\title{
Evaluation of Condition of Concrete Structures Using Ultrasonic Pulse Velocity Method
}

\author{
Seonguk Hong ${ }^{1}{ }^{\infty}$, Sangki Yoon ${ }^{2}$, Jonghyun Kim ${ }^{2}$, Changjong Lee ${ }^{2}$, Seunghun Kim ${ }^{2}$ \\ and Yongtaeg Lee ${ }^{2, *}$ \\ 1 Department of Architecture, Woosuk University, 66 Daehakro, Jincheoneup, Jincheongun, \\ Chungcheong bukdo 27841, Korea; suhong@woosuk.ac.kr \\ 2 Department of Architectural Engineering, Hanbat National University, 125 Dongseodero, Yuseonggu, \\ Daejeon 34158, Korea; looter2000@nate.com (S.Y.); klhoppaklh@naver.com (J.K.); \\ changjong1229@hanmail.net (C.L.); kimsh@hanbat.ac.kr (S.K.) \\ * Correspondence: ytlee@hanbat.ac.kr; Tel.: +82-42-821-1127
}

Received: 16 December 2019; Accepted: 14 January 2020; Published: 19 January 2020

\begin{abstract}
The purpose of this study is to estimate the compressive strength according to the age of the concrete structure using ultrasonic pulse velocity method. If the correlation between the ultrasonic pulse velocity and the compressive strength according to the age is derived, the compressive strength of the early age of the concrete structure can be estimated at the new construction site and the compressive strength of the existing structure can be estimated at the remodeling construction site. Concrete structural specimens were constructed with 123 specimens by setting 9 parameters based on the design compressive strength of $24,30,40 \mathrm{MPa}$ at 16, 20, 24, 48, 72, 120, 168, 360, $672 \mathrm{~h}$. For the calculation of the average ultrasonic velocity according to the age of concrete, it is carried out according to KS F 2731, ASTM C597 and ACI 228-2R, and the concrete compressive strength is carried out according to KS F 2405. From correlation between ultrasonic pulse velocity and compressive strength, this experiment suggests compressive strength estimation equation. The proposed estimation equation confirmed that it is possible to estimate the compressive strength of concrete according to its age using nondestructive test methods.
\end{abstract}

Keywords: evaluation; condition; concrete structures; compressive strength; ultrasonic pulse velocity method

\section{Introduction}

Structural safety diagnosis examines the safety and durability of an existing structure using destructive and nondestructive testing as well as visual observation and analysis. Nondestructive testing methods are widely used because they do not damage structures during the evaluation of their condition [1-3]. In addition, when the condition of concrete structures is evaluated, it is necessary to estimate the compressive strength through various methods for a diagnosis at the time of maintenance after construction, as well as for quality control during construction. Here, the focus is on diagnostic methods that use nondestructive testing methods suitable for examining the condition of a target building without damaging or destroying it. Moreover, many studies are being conducted on the evaluation of their applicability. Most of the previous studies conducted nondestructive testing for more than 28 days of age and examined quality control related to the concrete compressive strength at early ages, which is urgently required at construction sites [4-6]. However, these studies are scarce. Meeting the human desire to live in safe and convenient buildings as well as in cities is an important requirement of the current times. It would be desirable if there were no factors that threaten safety; however, various unexpected problems do occur in buildings. Under the premise of providing people 
with happiness and welfare through building safety, it is extremely important to establish a method of estimating the strengths of materials more accurately using nondestructive testing methods related to safety diagnosis. This is the first step of various methods to prevent accidents in concrete buildings and establish standards on precision safety diagnosis for buildings or for nondestructive testing methods.

The ultrasonic pulse velocity method estimates the compressive strength of concrete by measuring the ultrasonic pulse velocity from the pulse passing time between the transmitter and receiver at certain distances in a concrete structure, as described in ASTM C597-09 and KS F 2731. The ultrasonic pulse velocity can be used for evaluating concrete quality factors such as the elastic modulus, crack depth, and internal defects, and is applied by obtaining a correlation between the ultrasonic pulse velocity and the compressive strength.

This study proposes a compressive strength estimation equation from the correlation between the ultrasonic pulse velocity and the compressive strength according to the age of the concrete by applying the ultrasonic pulse velocity method, which is one of the nondestructive testing methods. Thus, the equation ultimately provides important data for establishing standards. The proposed concrete compressive strength estimation equation is expected to provide information on formwork removal at new construction sites by estimating the compressive strength of concrete structures at early ages. Further, it enables the quality control of materials at remodeled construction sites by accurately estimating the concrete compressive strength of the existing structures. Concrete specimens were fabricated to achieve the purpose of this study. Then, compressive strength testing and a nondestructive testing experiment were conducted using the specimens. In the experiment, a concrete compressive strength estimation equation was proposed by applying the ultrasonic pulse velocity method, one of the nondestructive testing methods, to identify the compressive strength estimation accuracy according to the age of the concrete structure. A total of 123 concrete specimens were fabricated by setting nine variables based on the ages of 16,20 , $24,48,72,120,168,360$, and $672 \mathrm{~h}$ for the designed strengths of 24,30 , and $40 \mathrm{MPa}$. To calculate the average ultrasonic pulse velocity according to the age of the concrete, an experiment was performed in accordance with KS F 2731, ACI 228-2R, and ASTM C 597-16. The concrete compressive strength testing was conducted in accordance with KS F 2405. Based on this, a method of evaluating the compressive strength estimation for concrete structures using the nondestructive testing method was established.

\section{Literature Review}

Studies on nondestructive testing methods for concrete structures began in the 1930s and increased in the 1970s when flaws were detected in unhardened concrete. In England, BS 1881 part 4 and part 5, which were standards on concrete testing methods for strength and others, were published, and BS 1881 part 201, which provided guidelines on the use of nondestructive testing for hardened concrete, was published in the 1980s. In the 2000s, standards on core testing, rebound hardness, and ultrasonic pulse velocity measurement were announced. In the U.S., an ACI 228 strength evaluation report with 38 papers on the standards of nondestructive evaluation and measurement area was published in the 1980s [1]. Based on this report, many studies have been conducted on the application of nondestructive testing methods to the diagnosis of concrete structures $[2,3,7,8]$.

The representative previous studies on nondestructive testing methods can be summarized beginning with the most recent as follows. In 2018, Panedpojaman and Tonnayopas (2018) conducted research on estimating the residual compressive strength of concrete after a fire using the concrete surface hardness [9]. Hong et al. (2016) and Hong and Cho (2006) conducted research on estimating the thickness of concrete as well as the defect locations inside a slab for concrete structures using the ultrasonic pulse velocity method and impact echo method [10,11]. In 2014, Azari, Nazarian and Yuan (2014) conducted research on the benefits of combining the impact echo method and the method of ultrasonic surface waves [4]. In 2013, Bogas et al. (2013) identified the difference between lightweight aggregate and normal aggregate using the ultrasonic pulse velocity method and proposed an estimation equation for predicting the compressive strength of concrete [12], and Furuich (2013) describes a fundamental uncertainty analysis for a flowrate measurement in a pipe using an ultrasonic Doppler 
velocity profile method and an evaluation of the estimated uncertainty by an actual flow calibration [13]. In 2011, Roh (2011) conducted research on estimating the corrosion of rebar in concrete walls using a self-potential survey method and infrared thermographic technique [14]. Baek et al. (2005) conducted research on a method of estimating the rebar corrosion level using infrared thermography data [15]. There are many other studies (Nadepour et al. (2017), Sabbag and Uyanik (2017), François Saint-Pierre et al. (2016), Nadepour et al. (2016) and Ghosh et al. (2018)) but most of these studies were conducted for a concrete age of 28 days or more, and the studies on quality control related to the compressive strength of concrete at early ages are insufficient $[5-7,16,17]$.

\section{Ultrasonic Pulse Velocity Method}

Structural safety diagnosis examines the status of the members in an existing structure for safety, durability, and usability using destructive and nondestructive testing as well as visual observation, measurement, and analysis. Nondestructive testing methods are used for the safety diagnosis of buildings. The definition of nondestructive testing methods includes a wide range. First, nondestructive testing refers to a diagnosis that does not deform concrete and other specimens by the test itself. Second, the test refers to methods that do not degrade the function of the structures. For example, core testing is also involved in the range of nondestructive testing. Third, the test refers to a diagnosis that causes less damage to structures than core testing.

For the construction management of structures and the judgment of durability of existing structures, it is necessary to be aware of the strength and condition of the structures. For structures under construction, typically, the compressive strengths of concrete specimens fabricated on site are checked. However, it is not possible to estimate accurate strength using the concrete of a structure and the concrete of a specimen; differences exist between on-site conditions (such as placing, compaction, and curing) and laboratory conditions. Therefore, measuring the compressive strength of the concrete of a structure in a nondestructive manner to secure accurate data is important. It is difficult to apply nondestructive evaluation to concrete because large uncertainties arise from differences in skill levels in the processes of concrete mixing, pouring, and curing; thus, related studies are being conducted constantly. Currently, the American Society of Testing Materials (ASTM) and International Standard Organization (ISO) are performing standardization work based on the research results for nondestructive testing methods. Nondestructive evaluation methods can be applied to various areas including concrete. Moreover, owing to advances in technology, new nondestructive evaluation methods have been developed.

The ultrasonic pulse velocity method estimates the compressive strength of concrete by measuring the ultrasonic pulse velocity from the pulse passing time between the transmitter and receiver at certain distances in a concrete structure, as described in ASTM C597-16 and KS F 2731. The ultrasonic pulse velocity can be used for evaluating concrete quality factors such as the elastic modulus, crack depth, and internal defects, and is applied by obtaining a correlation between the ultrasonic pulse velocity and the compressive strength. As ultrasound is affected by many factors owing to the non-uniform and nonspecific concrete density, estimating the accurate compressive strength of concrete using ultrasound alone is difficult in many cases. However, if the major conditions are similar, estimate the strength to a certain degree is possible because of the correlation between ultrasound and strength. ASTM C597-16 deals with a method of measuring the propagation velocity of the ultrasonic pulse in the longitudinal direction of concrete; it specifically indicates that stress waves are not applied to other types of radio waves. It also establishes appropriate safety and healthcare implementation standards and discusses the evaluation of the applicability of the management limit before use.

In the ultrasonic pulse velocity method, a short and strong electrical signal is transmitted to the transducer to make it vibrate according to the resonance frequency. The vibration of the transducer is transferred to the concrete by the contact medium and detected by the receiving transducer on the opposite side. As the time between the generation and arrival of the wave is recorded by the electrical equipment, the wave velocity can be obtained if the distance traveled by the wave is known. Assuming the behavior of concrete to be elastic, the propagation velocity of the wave can be expressed as Equation (1). 


$$
V_{p}=\sqrt{\frac{M}{\rho}}=\sqrt{\frac{E(1-v)}{\rho(1+v)(1-2 v)}}
$$

where,

$V_{p}$ : Velocity $(\mathrm{m} / \mathrm{s})$

$M$ : Constrained modulus (MPa)

$E$ : Young's modulus (MPa)

$\rho:$ Density $\left(\mathrm{kg} / \mathrm{m}^{3}\right)$

v: Poisson's ratio

As can be seen from Equation (1), the fundamental components of concrete that affect the wave velocity are the elastic modulus and density. The wave velocity is proportional to the square root of the elastic modulus and inversely proportional to the square root of the density. Factors affecting the wave velocity other than the strength are the water content and rebar. As for the water content, when concrete is changed from the dried state to the saturated state, the wave velocity increases by approximately $5 \%$. As for rebar, correction factors of 0.9 and 0.8 for the measured ultrasonic pulse velocity are proposed for perpendicular and parallel cases to the wave path, respectively. When a stress wave is propagated along a medium with the cylindrical shape in which axial displacement is allowed, the rod-wave velocity $\left(V_{c}\right)$ can be determined by Equation (2).

$$
V_{c}=\sqrt{\frac{E}{\rho}}
$$

As opposed to the $\mathrm{P}$ wave, the $\mathrm{S}$ wave causes only shear deformation without volume deformation, and the direction of the medium particle motion is perpendicular to the propagation direction. The velocity of the $S$ wave $\left(V_{s}\right)$ in Equation (3) is determined by the shear elastic modulus and density of the medium.

$$
V_{s}=\sqrt{\frac{G}{\rho}}
$$

where $G=\frac{E}{2(1+v)}$ : Shear elastic modulus (MPa)

The medium particles of Rayleigh waves propagating along the surface of a semi-infinite medium show their behavior in the form of a retrograde ellipse, and the behavior is opposite to the propagation direction of the wave on top of the ellipse. The velocity of the $\mathrm{R}$ wave $\left(V_{R}\right)$ in Equation (4) is a function of Poisson's ratio and can be obtained from the velocity of the $S$ wave.

$$
V_{R}=\frac{0.83+1.12 v}{1+v} V_{s}
$$

The ultrasonic pulse velocity method comprises direct, indirect, and angle beam methods according to the placement of the transmitter and receiver. The direct method is the most reliable one. When the characteristics of materials are evaluated by measuring the ultrasonic pulse velocity, the measurement accuracy must be very high. This means that testing equipment capable of generating appropriate pulses and accurately measuring the transit time through the tested material must be used. When the path lengths of pulses in a material are measured, the pulse velocity can be calculated using Equation (5).

$$
\text { Pulse velocity }=\frac{\text { Path length }}{\text { Transit time }}
$$

The typical equipment used for testing includes a pair of flexible data port channel (FDPC) platforms for recording and analyzing the original velocity, and receiver transducers $(54 \mathrm{kHz})$ for 
displaying the pulse velocity energy detected by the receiver. In the ultrasonic pulse velocity method inspection source, the receiver $(54-\mathrm{kHz}$ resonant transducer concrete) compressional wave and the ultrasonic pulse are included when transferring the distance known through waves, concrete, or wood. The signal is recorded by the computer, which is capable of amplifying, filtering, and viewing the signal. The computer also records the execution time and voltage amplitude. The pulse velocity is calculated by dividing the pulse path length by the transit time in concrete. The number shown on the measuring instrument represents the velocity passing from the transmitting transducer (Tx) to the receiving transducer $(\mathrm{Rx})$ when $\mathrm{Tx}$ and $\mathrm{Rx}$ are located at the appropriate positions on the surface of a member, and it is the value for the earliest pulse.

\section{Experiment}

The purpose of this study is to estimate the compressive strength of concrete using the ultrasonic pulse velocity method, one of the nondestructive testing methods, for compressive strength estimation according to the age of a concrete structure. As such, 123 concrete specimens were fabricated, as shown in Figure 1, by setting nine variables based on the ages of 16, 20, 24, 48, 72, 120, 168, 360, and $672 \mathrm{~h}$ for the designed strengths of 24, 30, and $40 \mathrm{MPa}$ using the mixing design shown in Table 1.

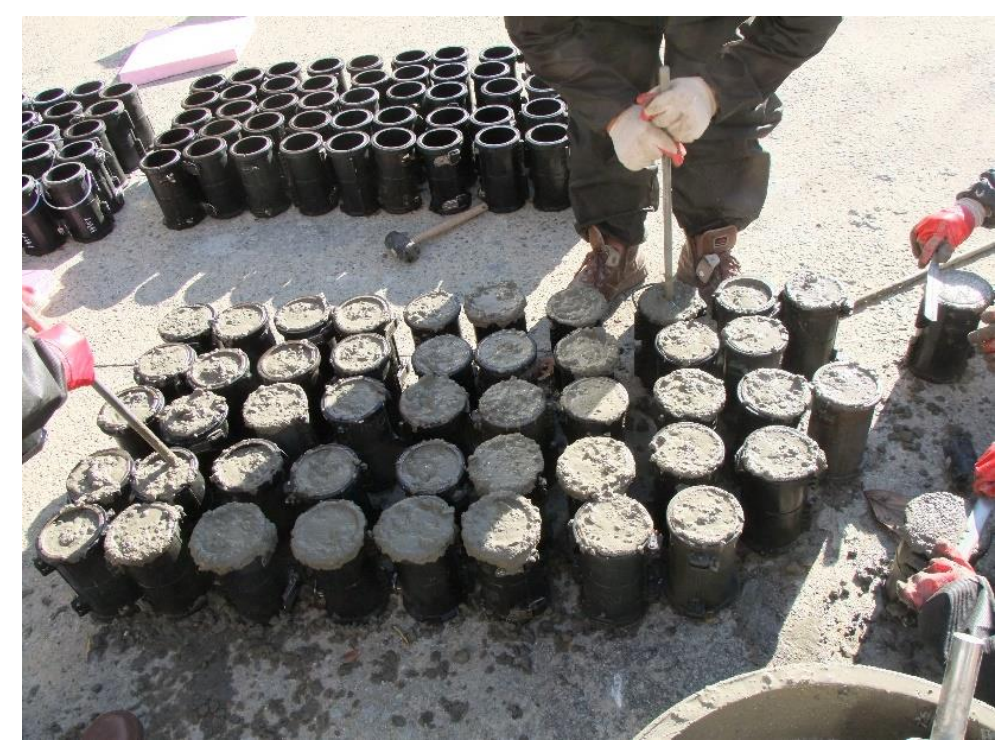

Figure 1. Concrete curing and concrete cylinder mold.

Table 1. Mix ratio of concrete.

\begin{tabular}{|c|c|c|c|c|c|}
\hline \multicolumn{6}{|c|}{ Designed Strength 24 MPa: Mix Ratio $\left(\mathrm{kg} / \mathrm{m}^{3}\right)$} \\
\hline Cement & Water & Fine Aggregate & Crushed Sand & Coarse Aggregate & High-Performance AE Reducing Agent \\
\hline 314 & 166 & 619 & 267 & 931 & 2.51 \\
\hline $\mathrm{W} / \mathrm{B}$ & & $52.9 \%$ & & S/a & $49 \%$ \\
\hline \multicolumn{6}{|c|}{ Designed Strength 30 MPa: Mix Ratio (kg/m³) } \\
\hline Cement & Water & Natural Sand & Crushed Sand & Coarse Aggregate & High-Performance AE Reducing Agent \\
\hline 383 & 170 & 557 & 240 & 948 & 3.06 \\
\hline $\mathrm{W} / \mathrm{B}$ & & $44.4 \%$ & & S/a & $45.9 \%$ \\
\hline \multicolumn{6}{|c|}{ Designed Strength 40 MPa: Mix Ratio $\left(\mathrm{kg} / \mathrm{m}^{3}\right)$} \\
\hline Cement & Water & Natural Sand & Crushed Sand & Coarse Aggregate & High-Performance AE Reducing Agent \\
\hline 465 & 160 & 532 & 230 & 944 & 3.72 \\
\hline $\mathrm{W} / \mathrm{B}$ & & $34.4 \%$ & & S/a & $44.9 \%$ \\
\hline
\end{tabular}


To calculate the average ultrasonic pulse velocity in concrete at early ages, the ultrasonic pulse velocity was measured 20 times at the center of the specimens, as shown in Figure 2, using ultrasonic pulse velocity measuring equipment from Olson in the U.S. in accordance with the standards of KS F 2731 and ACI 228-2R based on the ages of 16, 20, 24, 48, 72, 120, 168, 360, and $672 \mathrm{~h}$. For the compressive strength of concrete, the experiment was performed in accordance with KS F 2405, as shown in Figure 3.

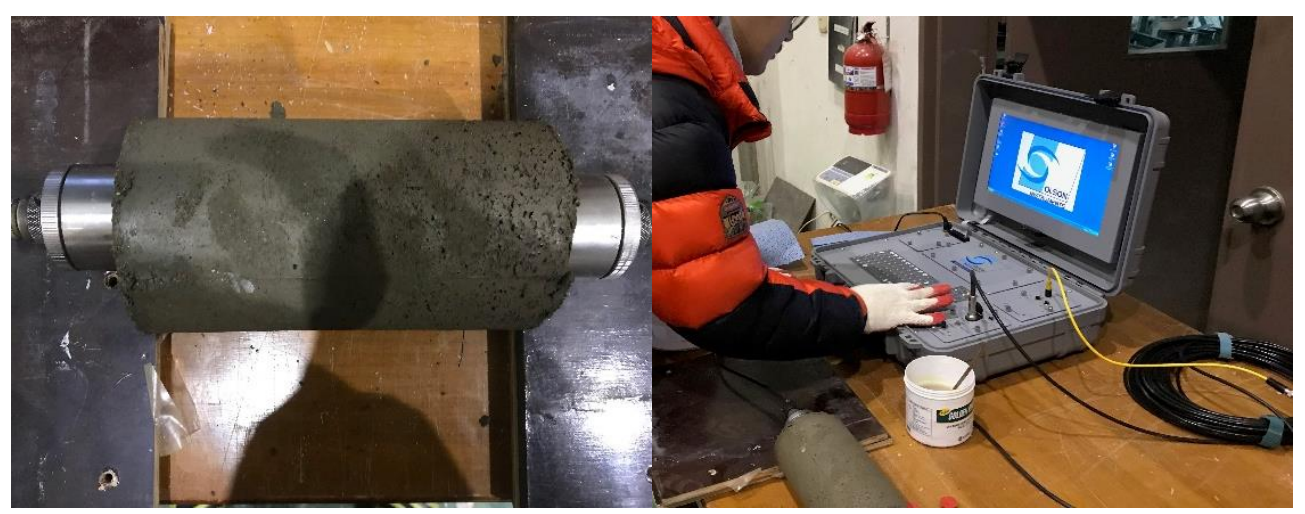

Figure 2. Experiment of ultrasonic pulse velocity method.

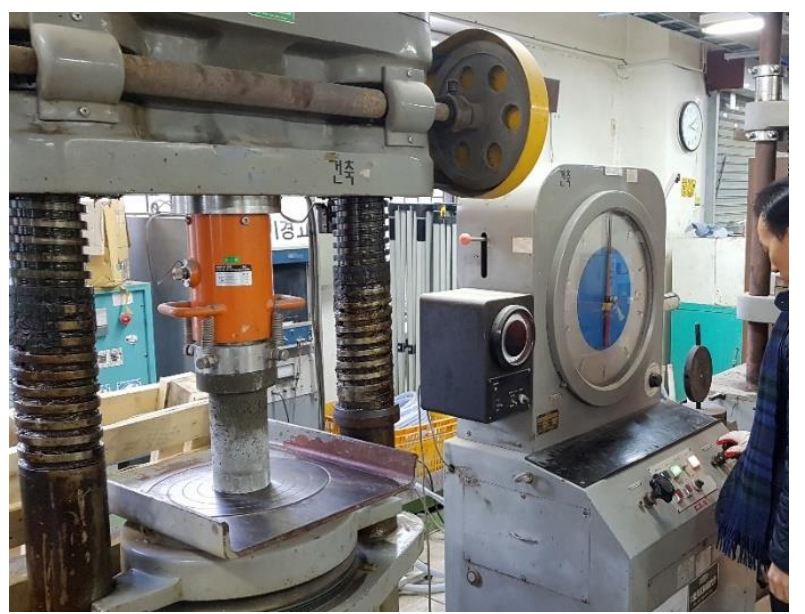

Figure 3. Testing method for compressive strength of molded concrete cylinders.

The top surfaces of the specimens were polished using a grinder for testing the compressive strength. The compressive strength was calculated after measuring the maximum load using a digital universal testing machine (UTM). The results of the experiment conducted for the 123 fabricated specimens to estimate the compressive strength of concrete using the ultrasonic pulse method are as follows. For the designed strength of $24 \mathrm{MPa}$, the ultrasonic pulse velocity in each specimen was measured at the ages of 16, 20,24, 48, 72, 120,168,360, and $672 \mathrm{~h}$, and compressive strength testing was conducted. The measurement results are listed in Table 2 . The measured ultrasonic pulse velocity for the designed concrete compressed strength of $24 \mathrm{MPa}$ was $96.4 \mathrm{~m} / \mathrm{s}$ at $16 \mathrm{~h}$ of age, $709.8 \mathrm{~m} / \mathrm{s}$ at $20 \mathrm{~h}, 1005.3 \mathrm{~m} / \mathrm{s}$ at $24 \mathrm{~h}, 2300.1 \mathrm{~m} / \mathrm{s}$ at $48 \mathrm{~h}, 2703.5 \mathrm{~m} / \mathrm{s}$ at $72 \mathrm{~h}, 2988.8 \mathrm{~m} / \mathrm{s}$ at $120 \mathrm{~h}, 3131.9 \mathrm{~m} / \mathrm{s}$ at $168 \mathrm{~h}$, $3382.6 \mathrm{~m} / \mathrm{s}$ at $360 \mathrm{~h}$, and $3381.1 \mathrm{~m} / \mathrm{s}$ at $672 \mathrm{~h}$. Figure 4 shows the ultrasonic pulse velocity according to age. As shown in the Figure 4, the wave velocity sharply increased from 16 to $72 \mathrm{~h}$ of age. It slowly increased to $120 \mathrm{~h}$ and then maintained a very slow increasing tendency up to $672 \mathrm{~h}$. 


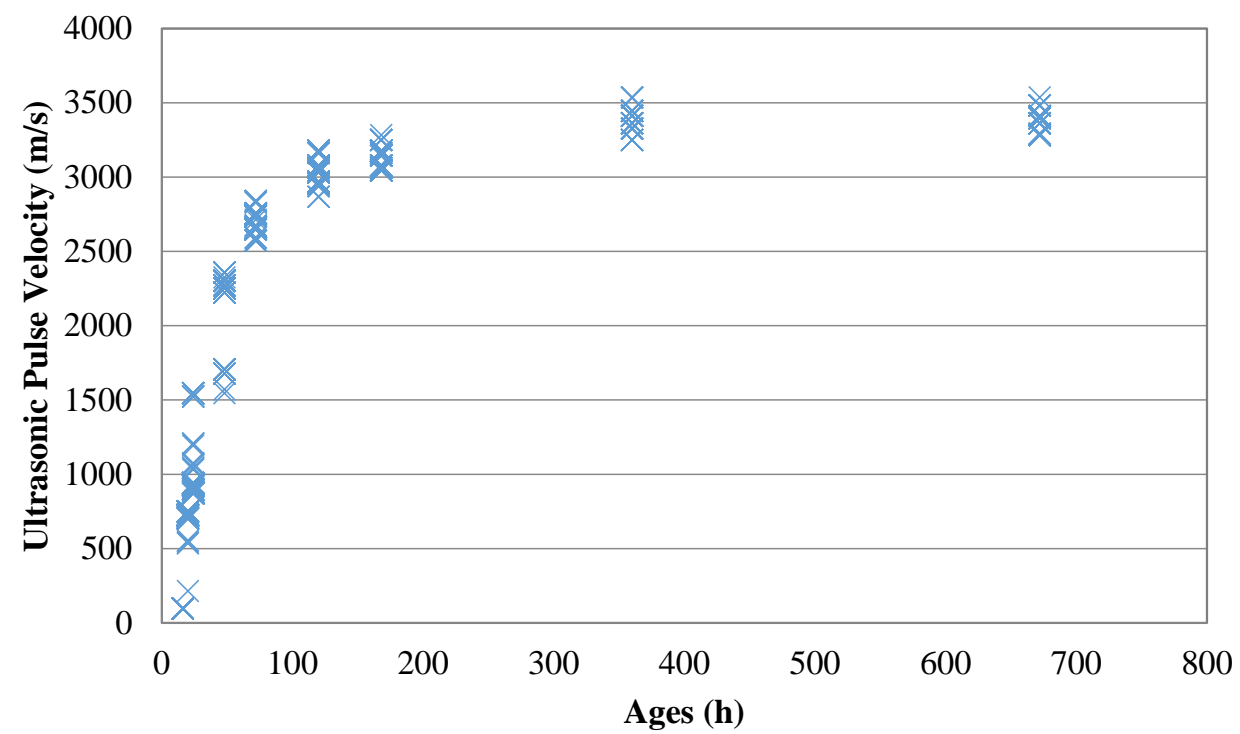

Figure 4. Ultrasonic pulse velocity with age (24 MPa).

Table 2. Experiment results.

\begin{tabular}{|c|c|c|c|c|c|c|c|c|c|c|c|c|c|}
\hline $\begin{array}{c}\text { Age } \\
\text { (h) }\end{array}$ & & & & Ultraso & $\begin{array}{r}\text { onic P } \\
(\mathrm{m}\end{array}$ & alse V & elocity & & & & Aver. & $\begin{array}{l}\text { Compressive } \\
\text { Strength (MPa) }\end{array}$ & Aver. \\
\hline \multirow{10}{*}{16} & 97 & 96 & 97 & 96 & 96 & 97 & 96 & 97 & 96 & 96 & \multirow{10}{*}{96.40} & \multirow{2}{*}{0.62} & \multirow{10}{*}{0.62} \\
\hline & 97 & 96 & 97 & 96 & 96 & 97 & 96 & 97 & 96 & 96 & & & \\
\hline & 97 & 96 & 97 & 96 & 96 & 97 & 96 & 97 & 96 & 96 & & \multirow{2}{*}{0.62} & \\
\hline & 97 & 96 & 97 & 96 & 96 & 97 & 96 & 97 & 96 & 96 & & & \\
\hline & 97 & 96 & 97 & 96 & 96 & 97 & 96 & 97 & 96 & 96 & & \multirow{2}{*}{0.62} & \\
\hline & 97 & 96 & 97 & 96 & 96 & 97 & 96 & 97 & 96 & 96 & & & \\
\hline & 97 & 96 & 97 & 96 & 96 & 97 & 96 & 97 & 96 & 96 & & \multirow{2}{*}{0.62} & \\
\hline & 97 & 96 & 97 & 96 & 96 & 97 & 96 & 97 & 96 & 96 & & & \\
\hline & 97 & 96 & 97 & 96 & 96 & 97 & 96 & 97 & 96 & 96 & & \multirow{2}{*}{0.62} & \\
\hline & 97 & 96 & 97 & 96 & 96 & 97 & 96 & 97 & 96 & 96 & & & \\
\hline \multirow{8}{*}{20} & 549 & 537 & 735 & 535 & 729 & 724 & 751 & 707 & 729 & 719 & \multirow{8}{*}{709.83} & \multirow{2}{*}{0.75} & \multirow{8}{*}{0.75} \\
\hline & 555 & 714 & 746 & 702 & 724 & 724 & 751 & 707 & 751 & 707 & & & \\
\hline & 719 & 719 & 751 & 707 & 724 & 724 & 751 & 707 & 724 & 719 & & \multirow{2}{*}{0.75} & \\
\hline & 214 & 719 & 746 & 702 & 729 & 724 & 751 & 707 & 751 & 712 & & & \\
\hline & 719 & 719 & 746 & 702 & 724 & 724 & 751 & 707 & 714 & 719 & & \multirow{2}{*}{0.75} & \\
\hline & 724 & 719 & 751 & 707 & 724 & 724 & 746 & 702 & 746 & 707 & & & \\
\hline & 724 & 724 & 751 & 702 & 729 & 724 & 751 & 702 & 724 & 724 & & \multirow{2}{*}{0.75} & \\
\hline & 719 & 724 & 751 & 702 & 729 & 724 & 751 & 702 & 751 & 707 & & & \\
\hline \multirow{10}{*}{24} & 891 & 1207 & 925 & 917 & 871 & 900 & 1207 & 942 & 1063 & 871 & \multirow{10}{*}{1005.27} & \multirow{2}{*}{0.87} & \multirow{10}{*}{0.92} \\
\hline & 900 & 1031 & 933 & 917 & 879 & 900 & 1523 & 942 & 925 & 879 & & & \\
\hline & 900 & 1523 & 933 & 1075 & 879 & 900 & 1546 & 942 & 925 & 879 & & \multirow{2}{*}{1.00} & \\
\hline & 891 & 1042 & 933 & 925 & 871 & 900 & 1546 & 942 & 925 & 879 & & & \\
\hline & 900 & 1042 & 942 & 917 & 879 & 900 & 1546 & 942 & 934 & 871 & & \multirow{2}{*}{1.00} & \\
\hline & 891 & 1546 & 942 & 925 & 879 & 900 & 1207 & 942 & 925 & 879 & & & \\
\hline & 900 & 1546 & 933 & 925 & 879 & 900 & 1546 & 942 & 934 & 879 & & \multirow{2}{*}{0.87} & \\
\hline & 900 & 1192 & 942 & 925 & 871 & 900 & 1523 & 942 & 925 & 879 & & & \\
\hline & 900 & 1546 & 942 & 925 & 871 & 900 & 1523 & 942 & 934 & 879 & & \multirow{2}{*}{0.87} & \\
\hline & 900 & 1064 & 942 & 925 & 879 & 900 & 1546 & 942 & 925 & 871 & & & \\
\hline
\end{tabular}


Table 2. Cont.

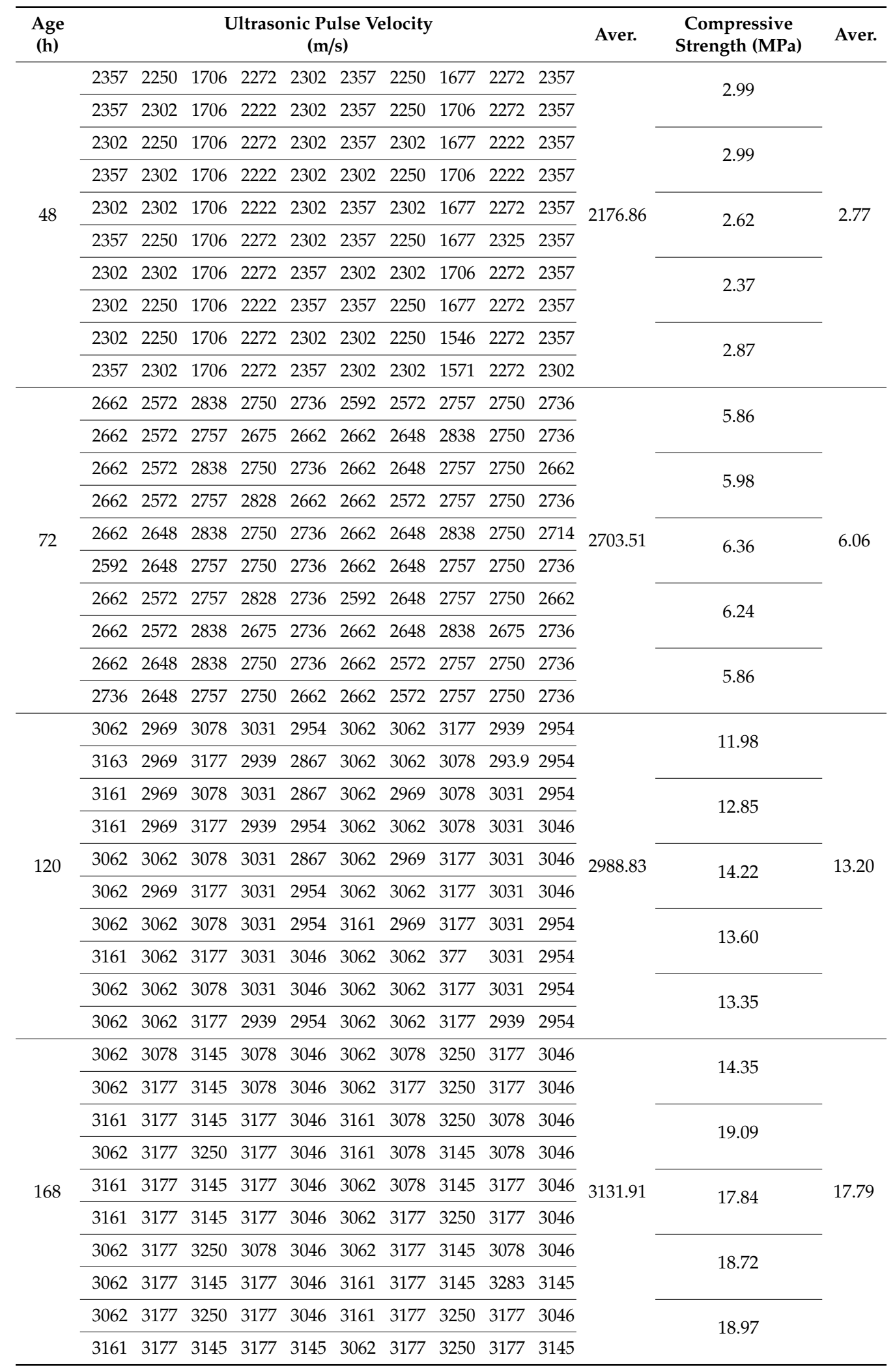


Table 2. Cont.

\begin{tabular}{|c|c|c|c|c|c|c|c|c|c|c|c|c|c|}
\hline \multirow[t]{2}{*}{$\begin{array}{c}\text { Age } \\
\text { (h) }\end{array}$} & \multicolumn{10}{|c|}{$\begin{array}{l}\text { Ultrasonic Pulse Velocity } \\
\text { (m/s) }\end{array}$} & \multirow{2}{*}{ Aver. } & \multirow{2}{*}{$\begin{array}{c}\begin{array}{c}\text { Compressive } \\
\text { Strength (MPa) }\end{array} \\
19.96\end{array}$} & \multirow[t]{2}{*}{ Aver } \\
\hline & 3362 & 3446 & 3413 & 3362 & 3327 & 3535 & 3250 & 3327 & 3413 & 3362 & & & \\
\hline \multirow{5}{*}{360} & 3362 & 3327 & 3413 & 3250 & 3327 & 3535 & 3250 & 3446 & 3413 & 3250 & \multirow{5}{*}{3382.57} & & \multirow{5}{*}{20.59} \\
\hline & 3362 & 3327 & 3413 & 3362 & 3446 & 3413 & 3250 & 3446 & 3413 & 3446 & & 2134 & \\
\hline & 3250 & 3446 & 3535 & 3250 & 3327 & 3413 & 3362 & 3446 & 3413 & 3446 & & 21.01 & \\
\hline & 3362 & 3327 & 3535 & 3362 & 3446 & 3413 & 3362 & 3327 & 3535 & 3413 & & \multirow{2}{*}{20.46} & \\
\hline & 3250 & 3327 & 3413 & 3362 & 3327 & 3413 & 3250 & 3446 & 3535 & 3413 & & & \\
\hline \multirow{6}{*}{672} & 3410 & 3362 & 3396 & 3410 & 3482 & 3283 & 3410 & 3482 & 3283 & 3410 & \multirow{6}{*}{3381.12} & 23.08 & \multirow{6}{*}{22.17} \\
\hline & 3410 & 3482 & 3396 & 3293 & 3362 & 3283 & 3410 & 3362 & 3283 & 3410 & & & \\
\hline & 3410 & 3362 & 3283 & 3410 & 3362 & 3396 & 3410 & 3362 & 3396 & 3482 & & 21.84 & \\
\hline & 3293 & 3362 & 3283 & 3293 & 3482 & 3283 & 3410 & 3362 & 3396 & 3482 & & & \\
\hline & 3410 & 3362 & 3283 & 3410 & 3482 & 3283 & 3410 & 3482 & 3283 & 3283 & & \multirow{2}{*}{21.59} & \\
\hline & 3410 & 3482 & 3396 & 3410 & 3362 & 3283 & 3537 & 3482 & 3283 & 3396 & & & \\
\hline
\end{tabular}

Figure 5 shows the concrete compressive strength according to age. As shown in the Figure 5, the concrete compressive strength was $2.58 \%$ of the designed strength at $16 \mathrm{~h}$ of age, $3.3 \%$ at $20 \mathrm{~h}$, $3.83 \%$ at $24 \mathrm{~h}, 11.54 \%$ at $48 \mathrm{~h}, 25.25 \%$ at $72 \mathrm{~h}, 55.00 \%$ at $120 \mathrm{~h}, 74.13 \%$ at $168 \mathrm{~h}, 85.79 \%$ at $360 \mathrm{~h}$, and $92.38 \%$ at $672 \mathrm{~h}$. In particular, it was found that the compressive strength increased as the age increased. Figure. 6 shows the correlation between the ultrasonic pulse velocity and the compressive strength. The Figure 6 shows that there is a certain correlation between the ultrasonic pulse velocity and the compressive strength.

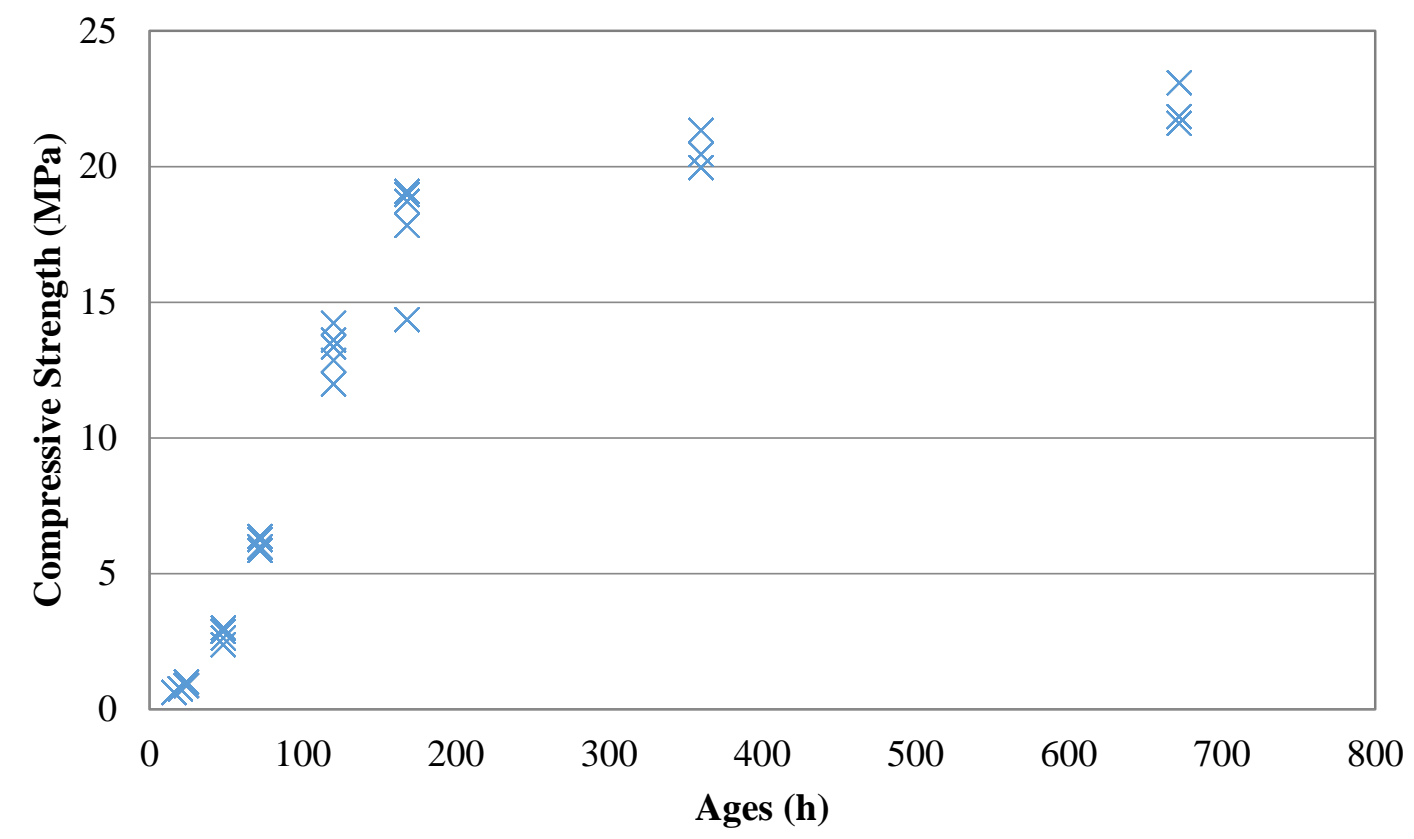

Figure 5. Compressive strength with age (24 MPa). 


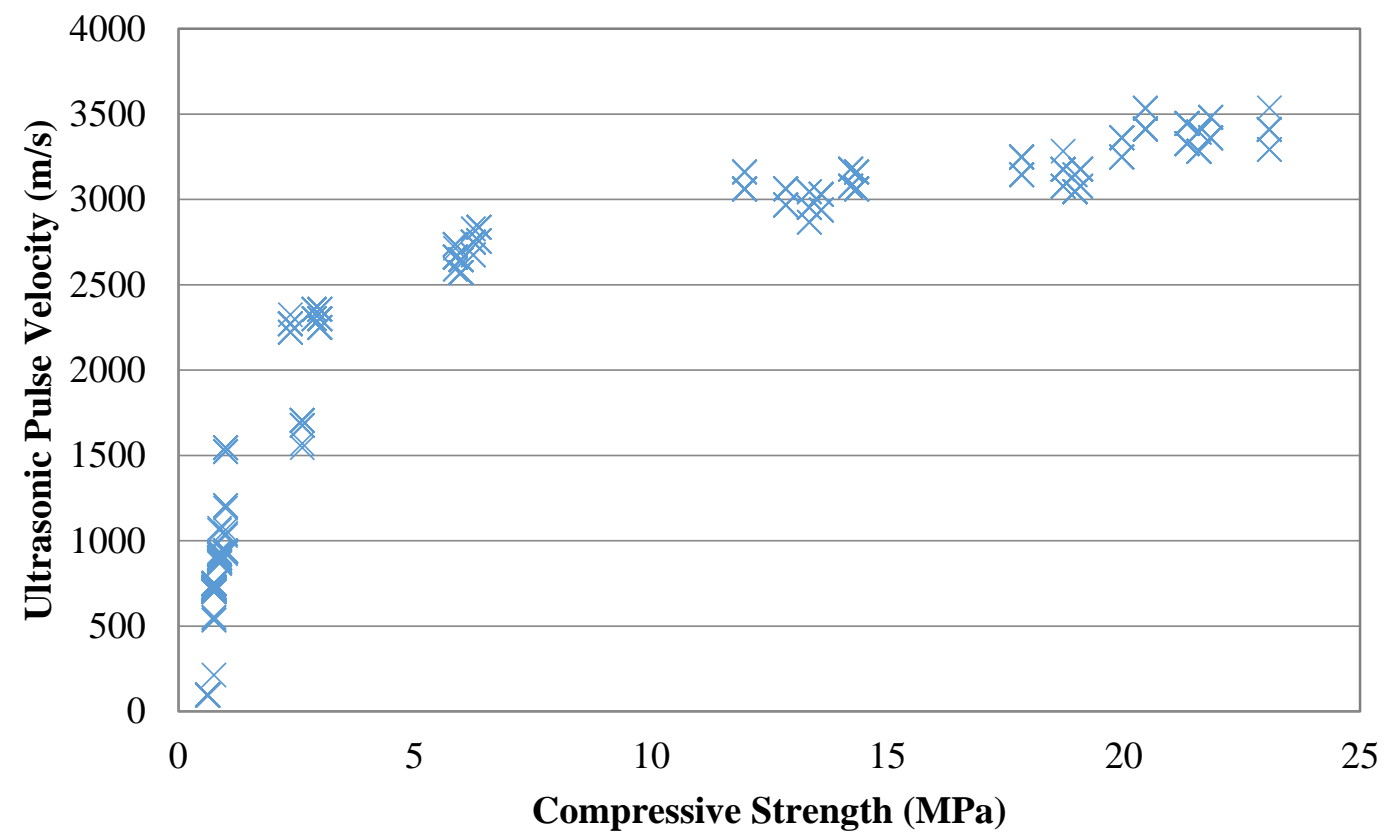

Figure 6. Relationship of ultrasonic pulse velocity and compressive strength (24 MPa).

For the designed concrete compressed strength of $30 \mathrm{MPa}$, the ultrasonic pulse velocity in each specimen was measured at the ages of $16,20,24,48,72,120,168,360$, and $672 \mathrm{~h}$, and compressive strength testing was conducted. The measurement results are listed in Table 3. The measured ultrasonic pulse velocity was $96.4 \mathrm{~m} / \mathrm{s}$ at $16 \mathrm{~h}$ of age, $96.0 \mathrm{~m} / \mathrm{s}$ at $20 \mathrm{~h}, 1010.03 \mathrm{~m} / \mathrm{s}$ at $24 \mathrm{~h}, 2451.8 \mathrm{~m} / \mathrm{s}$ at $48 \mathrm{~h}$, $2867.2 \mathrm{~m} / \mathrm{s}$ at $72 \mathrm{~h}, 3118.3 \mathrm{~m} / \mathrm{s}$ at $120 \mathrm{~h}, 3240.3 \mathrm{~m} / \mathrm{s}$ at $168 \mathrm{~h}, 3529.8 \mathrm{~m} / \mathrm{s}$ at $360 \mathrm{~h}$, and $3389.2 \mathrm{~m} / \mathrm{s}$ at $672 \mathrm{~h}$. Figure 7 shows the ultrasonic pulse velocity according to age. As shown in the Figure 7 , the wave velocity sharply increased from 16 to $72 \mathrm{~h}$ of age. It slowly increased to $120 \mathrm{~h}$ and then maintained a very slow increasing tendency up to $672 \mathrm{~h}$. Figure 8 shows the concrete compressive strength according to age. As shown in the figure, the concrete compressive strength was $2.07 \%$ of the designed strength at $16 \mathrm{~h}$ of age, $2.07 \%$ at $20 \mathrm{~h}, 3.73 \%$ at $24 \mathrm{~h}, 13.07 \%$ at $48 \mathrm{~h}, 30.67 \%$ at $72 \mathrm{~h}, 69.70 \%$ at $120 \mathrm{~h}, 84.70 \%$ at $168 \mathrm{~h}, 92.77 \%$ at $360 \mathrm{~h}$, and $95.40 \%$ at $672 \mathrm{~h}$. In particular, the compressive strength increased as the age increased.

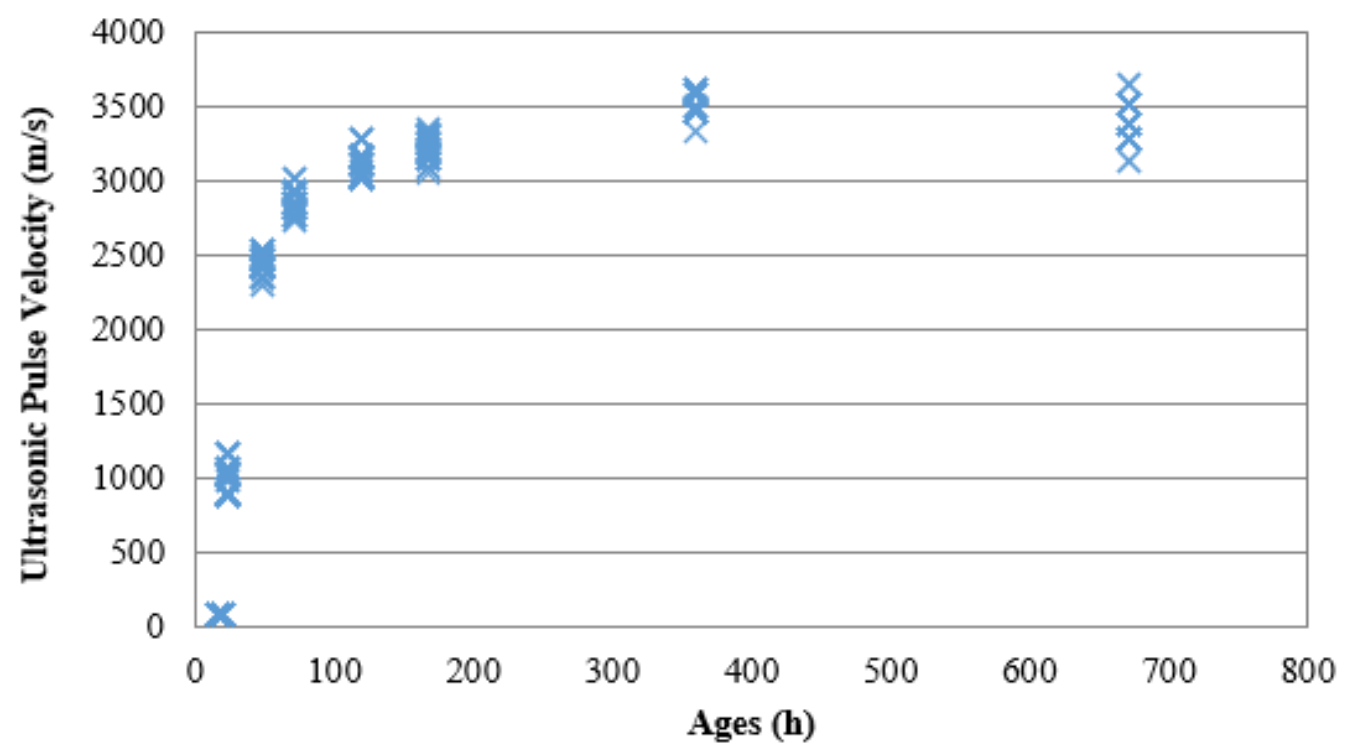

Figure 7. Ultrasonic pulse velocity with age (30 MPa). 


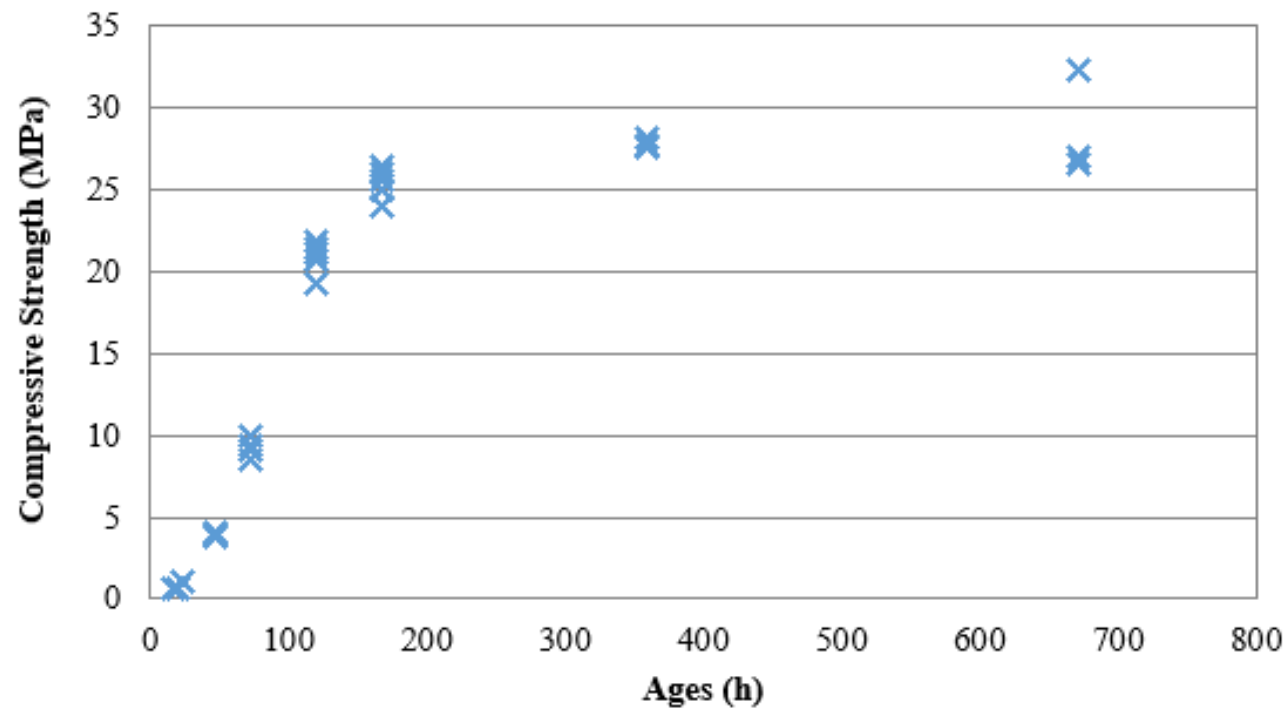

Figure 8. Compressive strength with age (30 MPa).

Table 3. Experiment results (30 MPa).

\begin{tabular}{|c|c|c|c|c|c|c|c|c|c|c|c|c|c|}
\hline Age (h) & & & Ultr & rasonic & c Pulse & e Velo & city $(\mathrm{n}$ & $\mathrm{n} / \mathrm{s})$ & & & Aver. & Compressive Strength (MPa) & Aver. \\
\hline \multirow{10}{*}{16} & 97 & 96 & 97 & 96 & 96 & 97 & 96 & 97 & 96 & 96 & \multirow{10}{*}{96.40} & \multirow{2}{*}{0.62} & \multirow{10}{*}{0.62} \\
\hline & 97 & 96 & 97 & 96 & 96 & 97 & 96 & 97 & 96 & 96 & & & \\
\hline & 97 & 96 & 97 & 96 & 96 & 97 & 96 & 97 & 96 & 96 & & \multirow{2}{*}{0.62} & \\
\hline & 97 & 96 & 97 & 96 & 96 & 97 & 96 & 97 & 96 & 96 & & & \\
\hline & 97 & 96 & 97 & 96 & 96 & 97 & 96 & 97 & 96 & 96 & & \multirow{2}{*}{0.62} & \\
\hline & 97 & 96 & 97 & 96 & 96 & 97 & 96 & 97 & 96 & 96 & & & \\
\hline & 97 & 96 & 97 & 96 & 96 & 97 & 96 & 97 & 96 & 96 & & \multirow{2}{*}{0.62} & \\
\hline & 97 & 96 & 97 & 96 & 96 & 97 & 96 & 97 & 96 & 96 & & & \\
\hline & 97 & 96 & 97 & 96 & 96 & 97 & 96 & 97 & 96 & 96 & & \multirow{2}{*}{0.62} & \\
\hline & 97 & 96 & 97 & 96 & 96 & 97 & 96 & 97 & 96 & 96 & & & \\
\hline \multirow{10}{*}{20} & 96 & 96 & 96 & 96 & 96 & 96 & 96 & 96 & 96 & 96 & \multirow{10}{*}{96.00} & \multirow{2}{*}{0.62} & \multirow{10}{*}{0.62} \\
\hline & 96 & 96 & 96 & 96 & 96 & 96 & 96 & 96 & 96 & 96 & & & \\
\hline & 96 & 96 & 96 & 96 & 96 & 96 & 96 & 96 & 96 & 96 & & \multirow{2}{*}{0.62} & \\
\hline & 96 & 96 & 96 & 96 & 96 & 96 & 96 & 96 & 96 & 96 & & & \\
\hline & 96 & 96 & 96 & 96 & 96 & 96 & 96 & 96 & 96 & 96 & & \multirow{2}{*}{0.62} & \\
\hline & 96 & 96 & 96 & 96 & 96 & 96 & 96 & 96 & 96 & 96 & & & \\
\hline & 96 & 96 & 96 & 96 & 96 & 96 & 96 & 96 & 96 & 96 & & \multirow{2}{*}{0.62} & \\
\hline & 96 & 96 & 96 & 96 & 96 & 96 & 96 & 96 & 96 & 96 & & & \\
\hline & 96 & 96 & 96 & 96 & 96 & 96 & 96 & 96 & 96 & 96 & & \multirow{2}{*}{0.62} & \\
\hline & 96 & 96 & 96 & 96 & 96 & 96 & 96 & 96 & 96 & 96 & & & \\
\hline \multirow{10}{*}{24} & 1069 & 888 & 1157 & 1036 & 900 & 1069 & 896 & 1164 & 904 & 908 & \multirow{10}{*}{1009.95} & \multirow{2}{*}{1.12} & \multirow{10}{*}{1.12} \\
\hline & 1058 & 1005 & 1164 & 1025 & 1020 & 1069 & 888 & 1164 & 1025 & 908 & & & \\
\hline & 1047 & 995 & 1164 & 1025 & 908 & 1069 & 985 & 1164 & 1025 & 908 & & \multirow{2}{*}{1.12} & \\
\hline & 1069 & 896 & 1164 & 1015 & 908 & 1058 & 888 & 1164 & 1036 & 908 & & & \\
\hline & 1069 & 888 & 1164 & 1025 & 900 & 1069 & 896 & 1164 & 904 & 908 & & \multirow{2}{*}{1.12} & \\
\hline & 1058 & 995 & 1164 & 896 & 908 & 1069 & 896 & 1164 & 1036 & 908 & & & \\
\hline & 1069 & 896 & 1164 & 1015 & 908 & 1069 & 896 & 1164 & 1036 & 908 & & \multirow{2}{*}{1.12} & \\
\hline & 1069 & 896 & 1164 & 904 & 908 & 1069 & 896 & 1164 & 1025 & 900 & & & \\
\hline & 1069 & 896 & 1164 & 896 & 908 & 1069 & 896 & 1164 & 1025 & 908 & & \multirow{2}{*}{1.12} & \\
\hline & 1069 & 896 & 1164 & 896 & 900 & 1069 & 995 & 1164 & 1025 & 908 & & & \\
\hline
\end{tabular}


Table 3. Cont.

\begin{tabular}{|c|c|c|c|c|c|c|c|c|c|c|c|c|c|}
\hline Age (h) & & & Ultr: & asonic & c Pulse & e Velo & city $(\mathrm{n}$ & & & & Aver. & Compressive Strength (MPa) & Aver. \\
\hline \multirow{10}{*}{48} & 2426 & 2475 & 2475 & 2414 & 2439 & 2426 & 2475 & 2475 & 2357 & 2439 & \multirow{10}{*}{2451.78} & \multirow{2}{*}{3.74} & \multirow{10}{*}{3.92} \\
\hline & 2426 & 2475 & 2538 & 2302 & 2439 & 2426 & 2475 & 2475 & 2357 & 2500 & & & \\
\hline & 2369 & 2475 & 2538 & 2357 & 2439 & 2426 & 2475 & 2538 & 2357 & 2439 & & \multirow{2}{*}{4.12} & \\
\hline & 2369 & 2475 & 2538 & 2357 & 2439 & 2426 & 2475 & 2538 & 2357 & 2500 & & & \\
\hline & 2426 & 2538 & 2475 & 2414 & 2439 & 2426 & 2475 & 2538 & 2414 & 2439 & & \multirow{2}{*}{3.87} & \\
\hline & 2426 & 2475 & 2538 & 2357 & 2439 & 2487 & 2475 & 2475 & 2414 & 2500 & & & \\
\hline & 2426 & 2475 & 2475 & 2302 & 2439 & 2426 & 2414 & 2538 & 2414 & 2500 & & \multirow{2}{*}{3.99} & \\
\hline & 2426 & 2475 & 2538 & 2302 & 2439 & 2487 & 2475 & 2538 & 2357 & 2500 & & & \\
\hline & 2487 & 2475 & 2538 & 2357 & 2439 & 2487 & 2538 & 2538 & 2414 & 2439 & & \multirow{2}{*}{3.87} & \\
\hline & 2426 & 2475 & 2538 & 2414 & 2500 & 2487 & 2475 & 2538 & 2357 & 2439 & & & \\
\hline \multirow{10}{*}{72} & 2842 & 2771 & 2823 & 2852 & 2852 & 2926 & 2771 & 2742 & 2852 & 2939 & \multirow{10}{*}{2867.16} & \multirow{2}{*}{9.11} & \multirow{10}{*}{9.21} \\
\hline & 2926 & 2852 & 2823 & 2852 & 2939 & 2926 & 2852 & 2823 & 2852 & 2939 & & & \\
\hline & 2926 & 2852 & 2909 & 2771 & 2939 & 3015 & 2852 & 2823 & 2771 & 2939 & & \multirow{2}{*}{9.98} & \\
\hline & 2926 & 2852 & 2823 & 2852 & 2852 & 2926 & 2852 & 2823 & 2852 & 2852 & & & \\
\hline & 2842 & 2852 & 2823 & 2771 & 2939 & 3015 & 2771 & 2742 & 2852 & 2852 & & \multirow{2}{*}{9.36} & \\
\hline & 2926 & 2852 & 2823 & 2852 & 2939 & 2926 & 2852 & 2823 & 2852 & 2852 & & & \\
\hline & 2926 & 2771 & 2823 & 2852 & 2939 & 3015 & 2852 & 2742 & 2852 & 2939 & & \multirow{2}{*}{9.11} & \\
\hline & 2926 & 2852 & 2823 & 2852 & 2939 & 2926 & 2852 & 2823 & 2771 & 2852 & & & \\
\hline & 3015 & 2852 & 2823 & 2771 & 2939 & 3015 & 2852 & 2823 & 2852 & 2939 & & \multirow{2}{*}{8.48} & \\
\hline & 3015 & 2852 & 2823 & 2852 & 2939 & 2926 & 2852 & 2909 & 2771 & 2852 & & & \\
\hline \multirow{10}{*}{120} & 3078 & 3177 & 3031 & 3031 & 3015 & 3177 & 3177 & 3031 & 3129 & 3015 & \multirow{10}{*}{3118.27} & \multirow{2}{*}{21.46} & \multirow{10}{*}{20.91} \\
\hline & 3177 & 3177 & 3031 & 3129 & 3015 & 3177 & 3283 & 3129 & 3129 & 3112 & & & \\
\hline & 3177 & 3283 & 3129 & 3129 & 3112 & 3177 & 3177 & 3129 & 3129 & 3015 & & \multirow{2}{*}{21.84} & \\
\hline & 3078 & 3177 & 3031 & 3129 & 3015 & 3177 & 3283 & 3031 & 3031 & 3015 & & & \\
\hline & 3177 & 3177 & 3129 & 3129 & 3015 & 3177 & 3177 & 3129 & 3129 & 3015 & & \multirow{2}{*}{19.34} & \\
\hline & 3177 & 3177 & 3031 & 3129 & 3015 & 3177 & 3283 & 3129 & 3031 & 3015 & & & \\
\hline & 3177 & 3177 & 3031 & 3129 & 3015 & 3283 & 3283 & 3031 & 3031 & 3112 & & 2121 & \\
\hline & 3177 & 3283 & 3031 & 3129 & 3015 & 3078 & 3177 & 3031 & 3129 & 3015 & & & \\
\hline & 3177 & 3283 & 3129 & 3129 & 3015 & 3177 & 3283 & 3031 & 3031 & 3112 & & 20.71 & \\
\hline & 3078 & 3177 & 3129 & 3031 & 3112 & 3177 & 3283 & 3031 & 3031 & 3015 & & & \\
\hline & 3200 & 3112 & 3250 & 3062 & 3193 & 3200 & 3216 & 3362 & 3161 & 3300 & & 2396 & \\
\hline & 3310 & 3216 & 3250 & 3266 & 3093 & 3200 & 3216 & 3250 & 3161 & 3193 & & & \\
\hline & 3310 & 3327 & 3250 & 3161 & 3093 & 3310 & 3327 & 3362 & 3266 & 3300 & & 2496 & \\
\hline & 3310 & 3216 & 3250 & 3161 & 3300 & 3310 & 3216 & 3362 & 3161 & 3193 & & & \\
\hline 168 & 3200 & 3327 & 3250 & 3161 & 3191 & 3310 & 3216 & 3250 & 3161 & 3300 & 3240.31 & 26.45 & 25.41 \\
\hline & 3310 & 3327 & 3250 & 3161 & 3300 & 3310 & 3327 & 3250 & 3161 & 3193 & & & \\
\hline & 3200 & 3216 & 3250 & 3266 & 3193 & 3200 & 3327 & 3362 & 3266 & 3300 & & 25.58 & \\
\hline & 3200 & 3327 & 3250 & 3266 & 3193 & 3200 & 3216 & 3250 & 3161 & 3300 & & & \\
\hline & 3200 & 3327 & 3250 & 3161 & 3193 & 3310 & 3327 & 3250 & 3161 & 3193 & & 2608 & \\
\hline & 3200 & 3216 & 3250 & 3161 & 3300 & 3200 & 3327 & 3250 & 3161 & 3300 & & & \\
\hline
\end{tabular}


Table 3. Cont.

\begin{tabular}{|c|c|c|c|c|c|c|c|c|c|c|c|c|c|}
\hline Age (h) & & & $\overline{\text { Ultr }}$ & asonic & c Pulse & e Velo & city (m & & & & Aver. & Compressive Strength (MPa) & Aver. \\
\hline \multirow{6}{*}{360} & 3464 & 3464 & 3629 & 3592 & 3464 & 3500 & 3592 & 3464 & 3629 & 3592 & \multirow{6}{*}{3529.82} & \multirow{2}{*}{28.20} & \multirow{6}{*}{27.83} \\
\hline & 3464 & 3464 & 3629 & 3592 & 3464 & 3500 & 3592 & 3344 & 3629 & 3464 & & & \\
\hline & 3464 & 3464 & 3629 & 3592 & 3464 & 3500 & 3592 & 3464 & 3500 & 3464 & & \multirow{2}{*}{27.58} & \\
\hline & 3464 & 3344 & 3500 & 3592 & 3464 & 3629 & 3592 & 3592 & 3500 & 3464 & & & \\
\hline & 3464 & 3464 & 3629 & 3464 & 3464 & 3629 & 3592 & 3464 & 3629 & 3500 & & \multirow{2}{*}{27.70} & \\
\hline & 3592 & 3464 & 3629 & 3592 & 3464 & 3629 & 3592 & 3464 & 3629 & 3629 & & & \\
\hline \multirow{6}{*}{672} & 3517 & 3283 & 3283 & 3517 & 3283 & 3145 & 3648 & 3396 & 3283 & 3648 & \multirow{6}{*}{3389.20} & 32,32 & \multirow{6}{*}{28.62} \\
\hline & 3517 & 3396 & 3283 & 3648 & 3283 & 3283 & 3517 & 3396 & 3283 & 3517 & & & \\
\hline & 3517 & 3283 & 3283 & 3517 & 3283 & 3283 & 3517 & 3396 & 3396 & 3396 & & 2695 & \\
\hline & 3517 & 3283 & 3283 & 3517 & 3396 & 3283 & 3517 & 3396 & 3396 & 3283 & & 20.90 & \\
\hline & 3517 & 3396 & 3283 & 3517 & 3396 & 3283 & 3648 & 3396 & 3283 & 3283 & & \multirow{2}{*}{26.58} & \\
\hline & 3517 & 3396 & 3283 & 3517 & 3396 & 3145 & 3517 & 3283 & 3145 & 3283 & & & \\
\hline
\end{tabular}

Figure 9 shows the correlation between the ultrasonic pulse velocity and the compressive strength. As shown in the Figure 9, there is a certain correlation between the ultrasonic pulse velocity and the compressive strength. For the designed concrete compressed strength of $40 \mathrm{MPa}$, the ultrasonic pulse velocity in each specimen was measured at the ages of 16, 20, 24, 48, 72, 120, 168, 360, and $672 \mathrm{~h}$, and compressive strength testing was conducted. The measurement results are listed in Table 4 . The measured ultrasonic pulse velocity was $96.4 \mathrm{~m} / \mathrm{s}$ at $16 \mathrm{~h}$ of age, $96.0 \mathrm{~m} / \mathrm{s}$ at $20 \mathrm{~h}, 1570.9 \mathrm{~m} / \mathrm{s}$ at $24 \mathrm{~h}$, $2543.5 \mathrm{~m} / \mathrm{s}$ at $48 \mathrm{~h}, 2952.5 \mathrm{~m} / \mathrm{s}$ at $72 \mathrm{~h}, 3157.6 \mathrm{~m} / \mathrm{s}$ at $120 \mathrm{~h}, 3321.9 \mathrm{~m} / \mathrm{s}$ at $168 \mathrm{~h}, 3474.6 \mathrm{~m} / \mathrm{s}$ at $360 \mathrm{~h}$, and $3455.7 \mathrm{~m} / \mathrm{s}$ at $672 \mathrm{~h}$. Figure 10 shows the ultrasonic pulse velocity according to age. As can be seen in the Figure 10, the wave velocity sharply increased from 16 to $72 \mathrm{~h}$ of age. It slowly increased to $120 \mathrm{~h}$ and then maintained a very slow increasing tendency up to $672 \mathrm{~h}$.

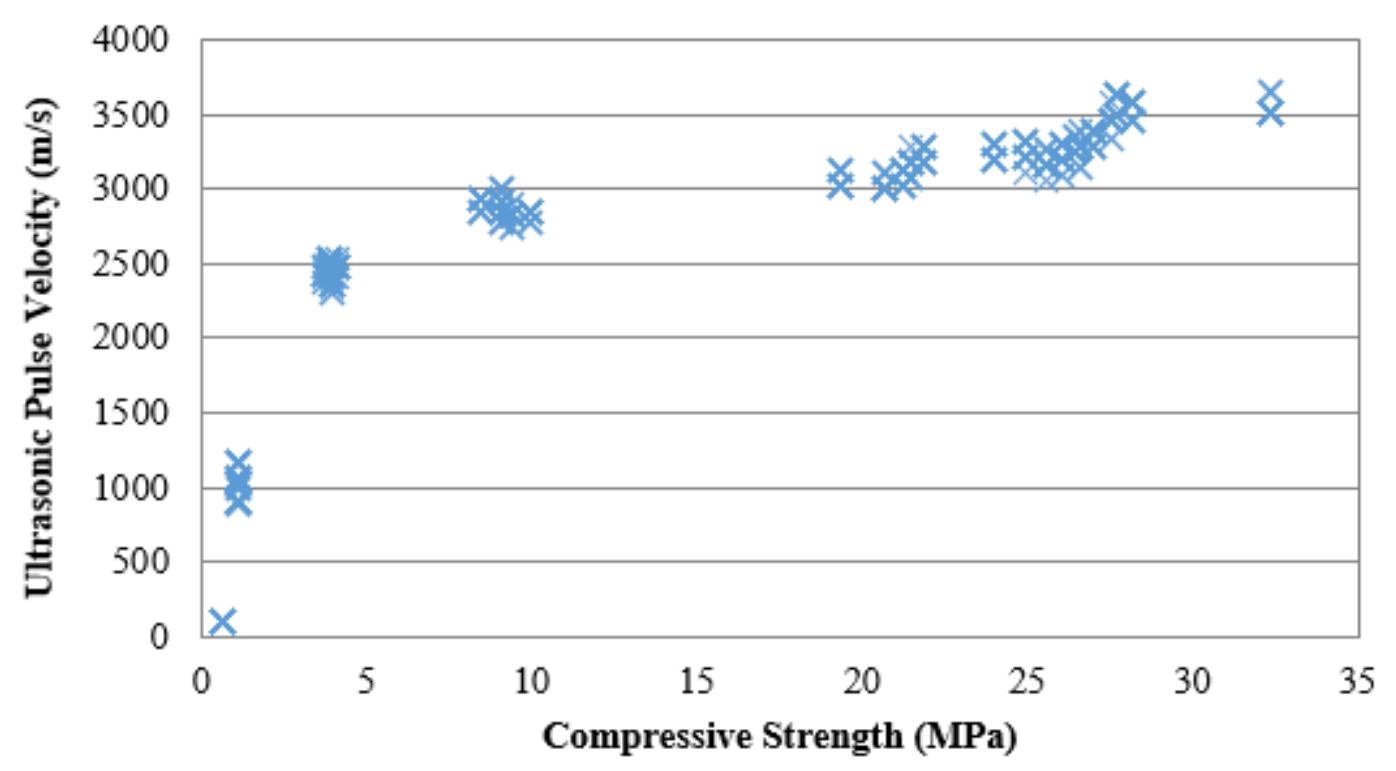

Figure 9. Relationship between ultrasonic pulse velocity and compressive strength (30 $\mathrm{MPa})$. 


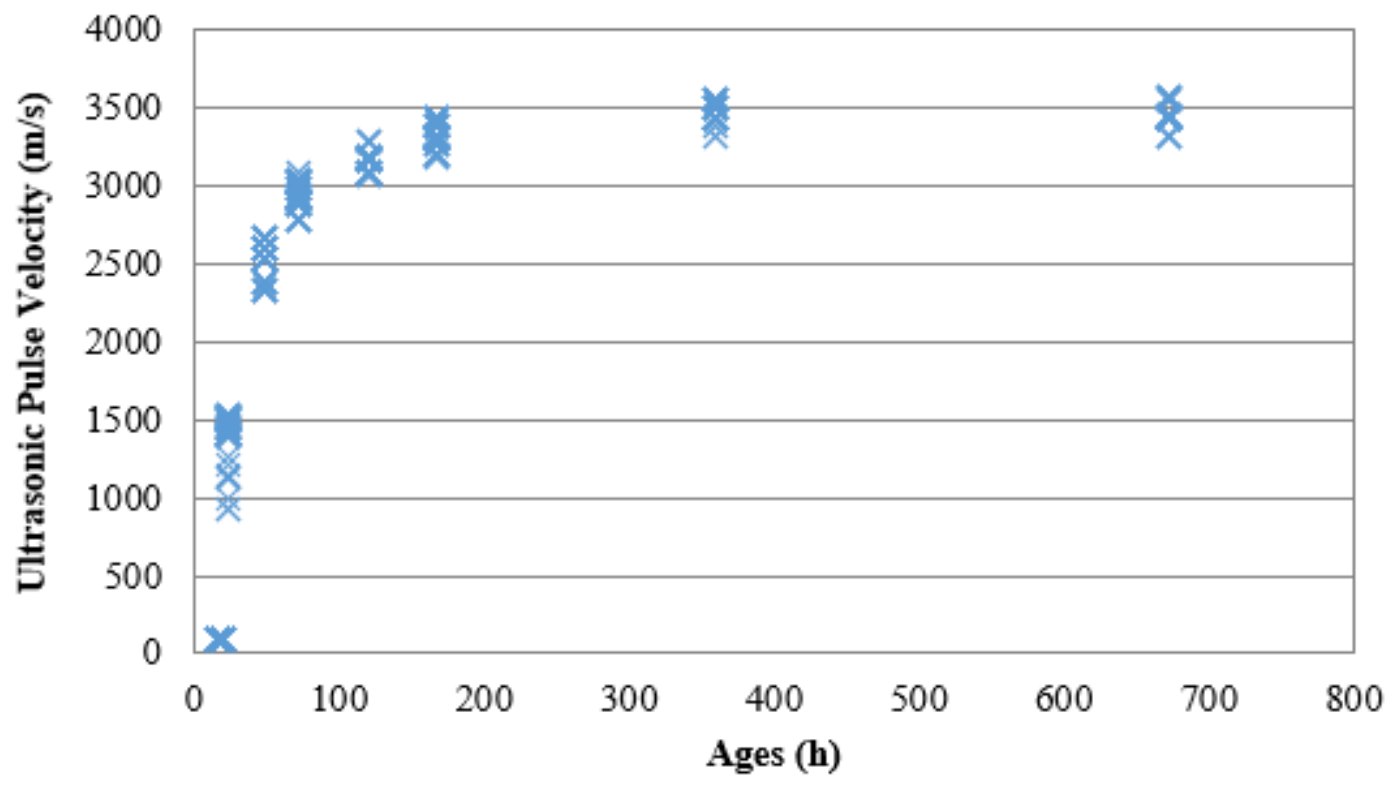

Figure 10. Ultrasonic pulse velocity with age (40 MPa).

Figure 11 shows the concrete compressive strength according to age. As shown in the Figure 11, the concrete compressive strength was $1.55 \%$ of the designed strength at $16 \mathrm{~h}$ of age, $1.55 \%$ at $20 \mathrm{~h}$, $2.80 \%$ at $24 \mathrm{~h}, 16.05 \%$ at $48 \mathrm{~h}, 38.33 \%$ at $72 \mathrm{~h}, 69.43 \%$ at $120 \mathrm{~h}, 83.85 \%$ at $168 \mathrm{~h}, 85.38 \%$ at $360 \mathrm{~h}$, and $85.48 \%$ at $672 \mathrm{~h}$. These results indicate that the compressive strength increased as the age increased. Figure 12 shows the correlation between the ultrasonic pulse velocity and the compressive strength. The Figure 12 shows that there is a certain correlation between the ultrasonic pulse velocity and the compressive strength.

Table 4. Experiment results (40 MPa).

\begin{tabular}{|c|c|c|c|c|c|c|c|c|c|c|c|c|c|}
\hline Age (h) & & & & ason & Pul & Vel & ity ( & & & & Aver. & Compressive Strength (MPa) & Aver. \\
\hline \multirow{10}{*}{16} & 97 & 96 & 97 & 96 & 96 & 97 & 96 & 97 & 96 & 96 & \multirow{10}{*}{96.40} & \multirow{2}{*}{0.62} & \multirow{10}{*}{0.62} \\
\hline & 97 & 96 & 97 & 96 & 96 & 97 & 96 & 97 & 96 & 96 & & & \\
\hline & 97 & 96 & 97 & 96 & 96 & 97 & 96 & 97 & 96 & 96 & & \multirow{2}{*}{0.62} & \\
\hline & 97 & 96 & 97 & 96 & 96 & 97 & 96 & 97 & 96 & 96 & & & \\
\hline & 97 & 96 & 97 & 96 & 96 & 97 & 96 & 97 & 96 & 96 & & \multirow{2}{*}{0.62} & \\
\hline & 97 & 96 & 97 & 96 & 96 & 97 & 96 & 97 & 96 & 96 & & & \\
\hline & 97 & 96 & 97 & 96 & 96 & 97 & 96 & 97 & 96 & 96 & & \multirow{2}{*}{0.62} & \\
\hline & 97 & 96 & 97 & 96 & 96 & 97 & 96 & 97 & 96 & 96 & & & \\
\hline & 97 & 96 & 97 & 96 & 96 & 97 & 96 & 97 & 96 & 96 & & \multirow{2}{*}{0.62} & \\
\hline & 97 & 96 & 97 & 96 & 96 & 97 & 96 & 97 & 96 & 96 & & & \\
\hline \multirow{10}{*}{20} & 96 & 96 & 96 & 96 & 96 & 96 & 96 & 96 & 96 & 96 & \multirow{10}{*}{96.00} & \multirow{2}{*}{0.62} & \multirow{10}{*}{0.62} \\
\hline & 96 & 96 & 96 & 96 & 96 & 96 & 96 & 96 & 96 & 96 & & & \\
\hline & 96 & 96 & 96 & 96 & 96 & 96 & 96 & 96 & 96 & 96 & & \multirow{2}{*}{0.62} & \\
\hline & 96 & 96 & 96 & 96 & 96 & 96 & 96 & 96 & 96 & 96 & & & \\
\hline & 96 & 96 & 96 & 96 & 96 & 96 & 96 & 96 & 96 & 96 & & \multirow{2}{*}{0.62} & \\
\hline & 96 & 96 & 96 & 96 & 96 & 96 & 96 & 96 & 96 & 96 & & & \\
\hline & 96 & 96 & 96 & 96 & 96 & 96 & 96 & 96 & 96 & 96 & & \multirow{2}{*}{0.62} & \\
\hline & 96 & 96 & 96 & 96 & 96 & 96 & 96 & 96 & 96 & 96 & & & \\
\hline & 96 & 96 & 96 & 96 & 96 & 96 & 96 & 96 & 96 & 96 & & \multirow{2}{*}{0.62} & \\
\hline & 96 & 96 & 96 & 96 & 96 & 96 & 96 & 96 & 96 & 96 & & & \\
\hline
\end{tabular}


Table 4. Cont.

\begin{tabular}{|c|c|c|c|c|c|c|c|c|c|c|c|c|c|}
\hline Age (h) & & & Ultri & asonic & c Pulse & Veloc & city (m & & & & Aver. & Compressive Strength (MPa) & Aver. \\
\hline \multirow{10}{*}{24} & 1414 & 1449 & 1401 & 1507 & 1149 & 1414 & 1515 & 1421 & 1530 & 1136 & \multirow{10}{*}{1570.92} & \multirow{2}{*}{1.12} & \multirow{10}{*}{1.12} \\
\hline & 1000 & 1492 & 1421 & 1485 & 1470 & 1394 & 1492 & 1442 & 1530 & 1515 & & & \\
\hline & 1394 & 1492 & 1442 & 1507 & 1449 & 1207 & 1515 & 1421 & 1507 & 1449 & & \multirow{2}{*}{1.12} & \\
\hline & 933 & 1492 & 1442 & 1507 & 1492 & 1414 & 1515 & 1421 & 1530 & 1492 & & & \\
\hline & 925 & 1492 & 1421 & 1507 & 1449 & 1394 & 1515 & 1421 & 1507 & 1515 & & \multirow{2}{*}{1.12} & \\
\hline & 1414 & 1270 & 1421 & 1530 & 1470 & 1414 & 1515 & 1442 & 1530 & 1492 & & & \\
\hline & 1394 & 1492 & 1421 & 15074 & 41136 & 1414 & 1515 & 1463 & 1507 & 1449 & & \multirow{2}{*}{1.25} & \\
\hline & 1414 & 1492 & 1421 & 1530 & 1136 & 1414 & 1492 & 1421 & 1530 & 1515 & & & \\
\hline & 1394 & 1515 & 1442 & 1530 & 1470 & 1414 & 1515 & 1442 & 1507 & 1492 & & \multirow{2}{*}{1.00} & \\
\hline & 1414 & 1492 & 1421 & 1530 & 1515 & 1414 & 1515 & 1421 & 1507 & 1470 & & & \\
\hline \multirow{10}{*}{48} & 2605 & 2605 & 2538 & 2538 & 2325 & 2605 & 2675 & 2605 & 2538 & 2325 & \multirow{10}{*}{2543.53} & \multirow{2}{*}{7.49} & \multirow{10}{*}{6.42} \\
\hline & 2605 & 2675 & 2538 & 2605 & 2380 & 2605 & 2675 & 2605 & 2605 & 2325 & & & \\
\hline & 2538 & 2605 & 2605 & 2538 & 2380 & 2605 & 2675 & 2538 & 2538 & 2380 & & \multirow{2}{*}{7.24} & \\
\hline & 2605 & 2675 & 2605 & 2538 & 2380 & 2538 & 2675 & 2605 & 2538 & 2380 & & & \\
\hline & 2538 & 2675 & 2605 & 2605 & 2380 & 2538 & 2675 & 2605 & 2538 & 2380 & & \multirow{2}{*}{6.49} & \\
\hline & 2605 & 2675 & 2538 & 2605 & 2380 & 2538 & 2675 & 2538 & 2605 & 2325 & & & \\
\hline & 2605 & 2675 & 2538 & 2538 & 2325 & 2605 & 2675 & 2605 & 2538 & 2325 & & \multirow{2}{*}{5.99} & \\
\hline & 2538 & 2675 & 2605 & 2605 & 2325 & 2538 & 2605 & 2605 & 2538 & 2325 & & & \\
\hline & 2605 & 2605 & 2605 & 2538 & 2380 & 2538 & 2605 & 2605 & 2538 & 2380 & & \multirow{2}{*}{4.87} & \\
\hline & 2538 & 2605 & 2538 & 2538 & 2325 & 2538 & 2675 & 2538 & 2605 & 2325 & & & \\
\hline \multirow{10}{*}{72} & 2984 & 2887 & 2926 & 3031 & 3030 & 2984 & 2785 & 2926 & 3031 & 3030 & \multirow{10}{*}{2952.45} & \multirow{2}{*}{15.10} & \multirow{10}{*}{15.33} \\
\hline & 2984 & 2785 & 3015 & 2939 & 2941 & 2897 & 2785 & 2926 & 2939 & 2941 & & & \\
\hline & 2984 & 2887 & 3015 & 3031 & 2941 & 2984 & 2887 & 3015 & 2939 & 2941 & & \multirow{2}{*}{16.10} & \\
\hline & 3078 & 2887 & 3015 & 3031 & 2941 & 2894 & 2785 & 2926 & 2939 & 3030 & & & \\
\hline & 2984 & 2785 & 2926 & 2939 & 2941 & 2984 & 2887 & 3015 & 2939 & 3030 & & \multirow{2}{*}{13.48} & \\
\hline & 2984 & 2887 & 2926 & 2939 & 2941 & 2984 & 2887 & 3015 & 3031 & 2941 & & & \\
\hline & 2984 & 2785 & 3015 & 2939 & 3030 & 2984 & 2887 & 2926 & 3031 & 3030 & & 16.35 & \\
\hline & 2897 & 2887 & 3015 & 2939 & 3030 & 2984 & 2785 & 3015 & 3031 & 2941 & & & \\
\hline & 2897 & 2887 & 3015 & 2939 & 3030 & 3078 & 2887 & 3015 & 2939 & 3030 & & 15,60 & \\
\hline & 2984 & 2785 & 3015 & 3031 & 2941 & 2984 & 2785 & 3015 & 3031 & 2941 & & & \\
\hline & 3093 & 3161 & 3177 & 3177 & 3093 & 3193 & 3062 & 3177 & 3177 & 3093 & & 27.45 & \\
\hline & 3193 & 3161 & 3177 & 3177 & 3093 & 3193 & 3161 & 3177 & 3177 & 3193 & & & \\
\hline & 3093 & 3062 & 3177 & 3177 & 3093 & 3193 & 3161 & 3078 & 3283 & 3093 & & 28.07 & \\
\hline & 3193 & 3161 & 3177 & 3177 & 3093 & 3193 & 3161 & 3177 & 3283 & 3193 & & & \\
\hline 120 & 3093 & 3062 & 3078 & 3283 & 3093 & 3193 & 3161 & 3078 & 3177 & 3093 & 3157.61 & 27.45 & 27.77 \\
\hline & 3093 & 3161 & 3078 & 3177 & 3193 & 3193 & 3161 & 3177 & 3177 & 3193 & & & \\
\hline & 3193 & 3161 & 3078 & 3177 & 3193 & 3193 & 3161 & 3078 & 3283 & 3093 & & 28.07 & \\
\hline & 3193 & 3161 & 3078 & 3283 & 3093 & 3093 & 3161 & 3177 & 3177 & 3193 & & & \\
\hline & 3093 & 3161 & 3177 & 3177 & 3093 & 3193 & 3161 & 3177 & 3177 & 3193 & & 27.83 & \\
\hline & 3193 & 3161 & 3177 & 3177 & 3193 & 3193 & 3161 & 3078 & 3177 & 3193 & & & \\
\hline
\end{tabular}


Table 4. Cont.

\begin{tabular}{|c|c|c|c|c|c|c|c|c|c|c|c|c|c|}
\hline Age (h) & & & Ultr & casonic & Pulse & Velo & city $(n$ & //s) & & & Aver. & Compressive Strength (MPa) & Aver. \\
\hline \multirow{10}{*}{168} & 3316 & 3300 & 3266 & 3316 & 3209 & 3316 & 3193 & 3379 & 3316 & 3209 & \multirow{10}{*}{3321.93} & \multirow{2}{*}{32.57} & \multirow{10}{*}{33.54} \\
\hline & 3316 & 3193 & 3378 & 3316 & 3316 & 3431 & 3300 & 3379 & 3316 & 3316 & & & \\
\hline & 3316 & 3300 & 3379 & 3316 & 3209 & 3431 & 3300 & 3379 & 3316 & 3209 & & \multirow{2}{*}{33.94} & \\
\hline & 3316 & 3193 & 3379 & 3316 & 3316 & 3431 & 3300 & 3266 & 3316 & 3316 & & & \\
\hline & 3431 & 3300 & 3379 & 3316 & 3316 & 3431 & 3300 & 3379 & 3431 & 3316 & & \multirow{2}{*}{33.69} & \\
\hline & 3431 & 3300 & 3379 & 3316 & 3209 & 3431 & 3413 & 3266 & 3431 & 3209 & & & \\
\hline & 3316 & 3300 & 3379 & 3316 & 3209 & 3316 & 3300 & 3379 & 3431 & 3316 & & \multirow{2}{*}{33.94} & \\
\hline & 3316 & 3300 & 3379 & 3316 & 3209 & 3316 & 3300 & 3379 & 3431 & 3209 & & & \\
\hline & 3316 & 3300 & 3266 & 3431 & 3316 & 3316 & 3300 & 3266 & 3316 & 3316 & & \multirow{2}{*}{33.57} & \\
\hline & 3316 & 3300 & 3379 & 3431 & 3316 & 3431 & 3300 & 3266 & 3316 & 3209 & & & \\
\hline \multirow{6}{*}{360} & 3500 & 3431 & 3431 & 3500 & 3553 & 3431 & 3500 & 3431 & 3431 & 3379 & \multirow{6}{*}{3474.60} & \multirow{2}{*}{36.06} & \multirow{6}{*}{34.15} \\
\hline & 3500 & 3553 & 3431 & 3500 & 3553 & 3431 & 3500 & 3553 & 3431 & 3500 & & & \\
\hline & 3500 & 3431 & 3431 & 3500 & 3553 & 3316 & 3500 & 3431 & 3431 & 3553 & & \multirow{2}{*}{33.94} & \\
\hline & 3500 & 3431 & 3431 & 3500 & 3553 & 3431 & 3379 & 3553 & 3316 & 3553 & & & \\
\hline & 3500 & 3553 & 3431 & 3500 & 3431 & 3431 & 3500 & 3553 & 3431 & 3431 & & \multirow{2}{*}{32.44} & \\
\hline & 3500 & 3431 & 3431 & 3500 & 3553 & 3431 & 3500 & 3553 & 3431 & 3553 & & & \\
\hline \multirow{6}{*}{672} & 3316 & 3431 & 3448 & 3431 & 3431 & 3571 & 3316 & 3431 & 3448 & 3431 & \multirow{6}{*}{3455.70} & \multirow{2}{*}{39.55} & \multirow{6}{*}{34.19} \\
\hline & 3431 & 3431 & 3571 & 3431 & 3553 & 3448 & 3316 & 3553 & 3571 & 3431 & & & \\
\hline & 3431 & 3431 & 3571 & 3431 & 3553 & 3571 & 3431 & 3431 & 3448 & 3431 & & \multirow{2}{*}{31.44} & \\
\hline & 3316 & 3431 & 3448 & 3431 & 3431 & 3448 & 3431 & 3553 & 3448 & 3431 & & & \\
\hline & 3431 & 3431 & 3448 & 3431 & 3553 & 3448 & 3316 & 3431 & 3448 & 3448 & & \multirow{2}{*}{31.57} & \\
\hline & 3431 & 3431 & 3571 & 3431 & 3431 & 3571 & 3431 & 3431 & 3571 & 3571 & & & \\
\hline
\end{tabular}

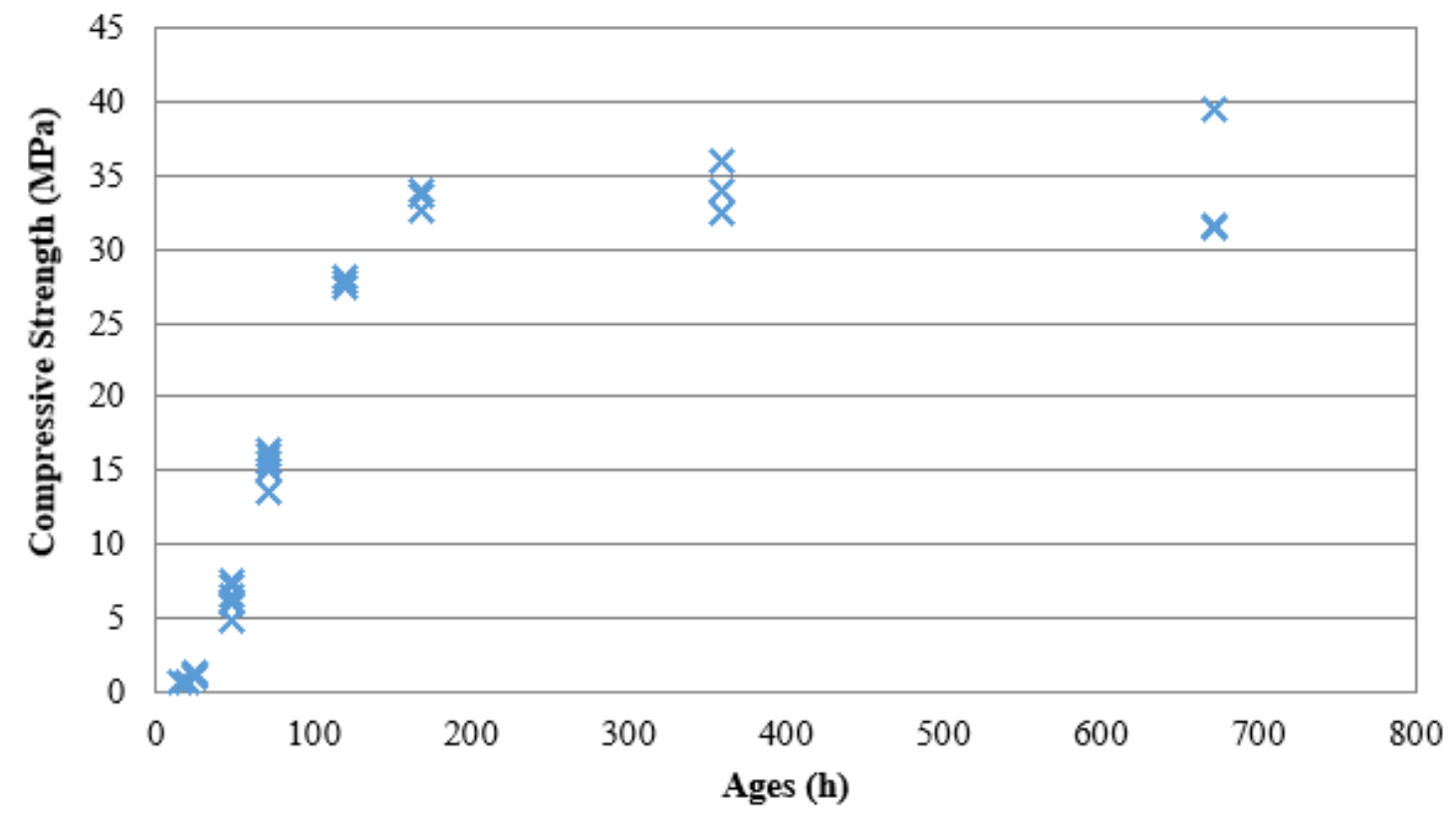

Figure 11. Compressive strength with age (40 MPa). 


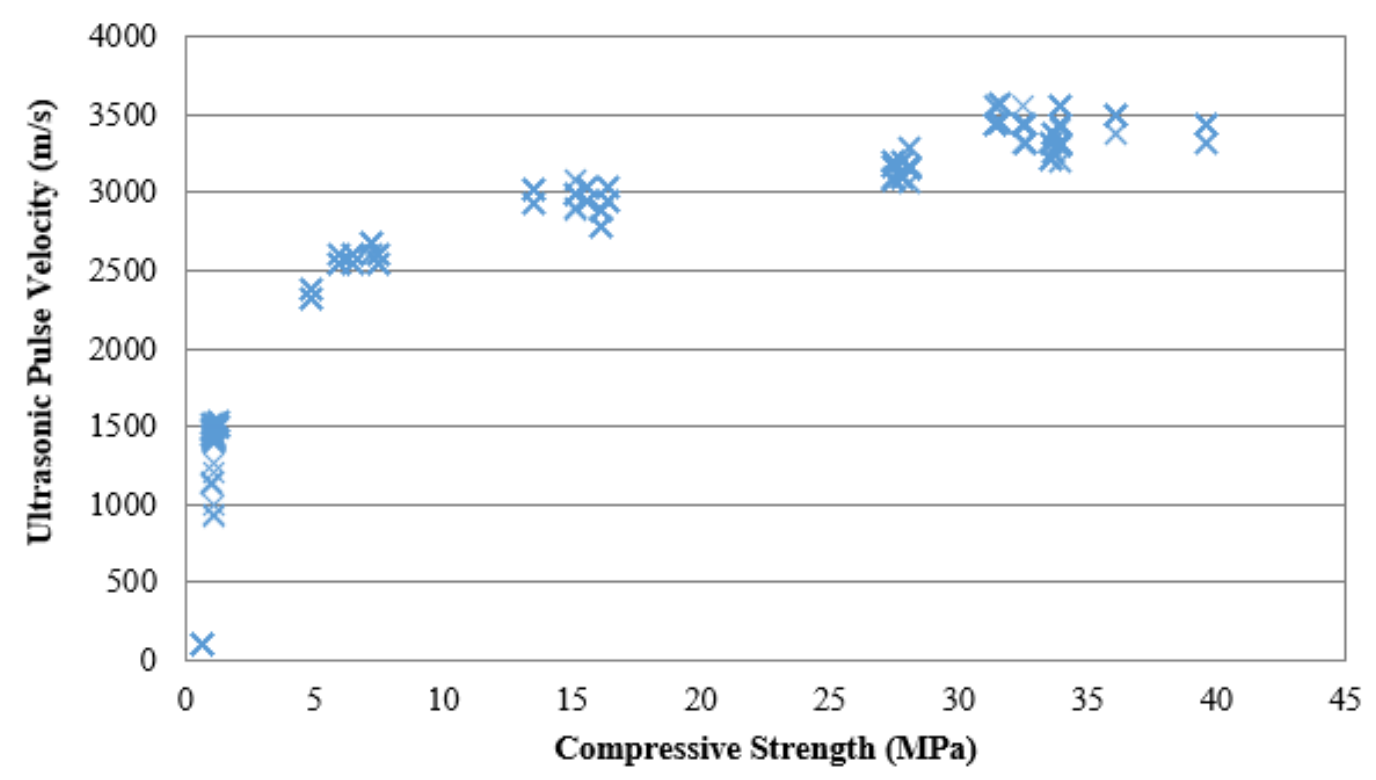

Figure 12. Relationship of ultrasonic pulse velocity and compressive strength (40 MPa).

\section{Discussion}

Based on the experiment results, this study attempted to estimate the compressive strengths of concrete structures by identifying the correlation between the concrete compressive strength and the ultrasonic pulse velocity according to age. Figure 13 shows the correlation between the ultrasonic pulse velocity and the compressive strength derived from the 123 concrete specimens fabricated by setting nine variables based on the ages of $16,20,24,48,72,120,168,360$, and $672 \mathrm{~h}$ for the designed strengths of 24,30 , and $40 \mathrm{MPa}$. From the derived correlation, a concrete compressive strength estimation equation is proposed as Equation (6).

$$
\mathrm{y}=832.75 \ln (\mathrm{x})+844.9, R^{2}=0.94
$$

where

$\mathrm{x}$ : concrete compressive strength $(\mathrm{MPa})$

$\mathrm{y}$ : ultrasonic pulse velocity $(\mathrm{m} / \mathrm{s})$

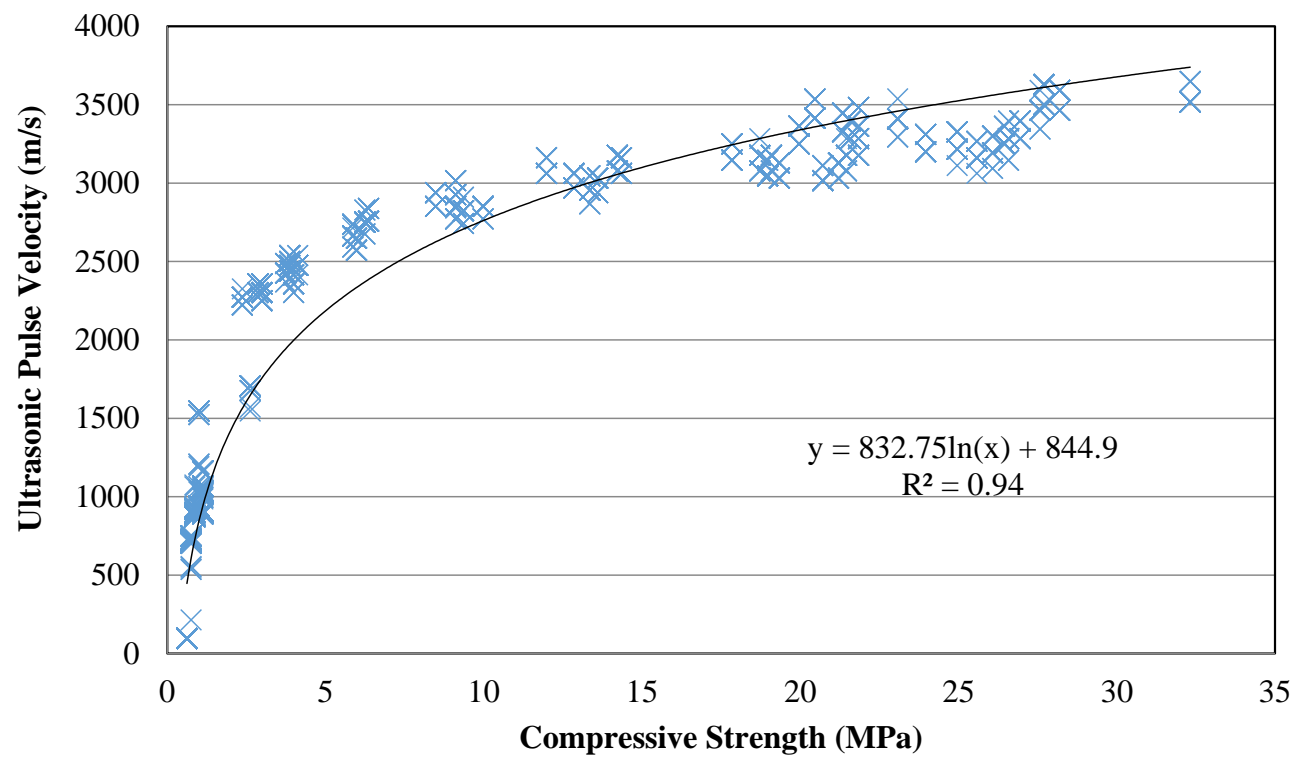

Figure 13. Estimation equation of compressive strength. 


\section{Conclusions}

The purpose of this study was to estimate the compressive strength of concrete using the ultrasonic pulse velocity method, one of the nondestructive testing methods, for compressive strength estimation according to the age of the concrete. To achieve this purpose, a total of 123 concrete specimens were fabricated by setting nine variables based on the ages of $16,20,24,48,72,120,168,360$, and $672 \mathrm{~h}$ for the designed strengths of 24,30, and $40 \mathrm{MPa}$. An experiment was performed to estimate the compressive strength of concrete according to its age. From the experiment, the following conclusions were obtained:

For the designed strengths of 24,30 , and $40 \mathrm{MPa}$, the ultrasonic pulse velocity in each specimen sharply increased from 16 to $72 \mathrm{~h}$ of age. It slowly increased to $120 \mathrm{~h}$ and then maintained a very slow increasing tendency up to $672 \mathrm{~h}$. As a result of measuring the compressive strength, the average compressive strength was $2.07 \%$ of the designed strength at $16 \mathrm{~h}$ of age, $2.25 \%$ at $20 \mathrm{~h}, 3.21 \%$ at $24 \mathrm{~h}$, $13.55 \%$ at $48 \mathrm{~h}, 31.42 \%$ at $72 \mathrm{~h}, 64.71 \%$ at $120 \mathrm{~h}, 80.89 \%$ at $168 \mathrm{~h}, 87.98 \%$ at $360 \mathrm{~h}$, and $91.09 \%$ at $672 \mathrm{~h}$. From the analysis of the correlation between the ultrasonic pulse velocity and the compressive strength, a concrete compressive strength estimation equation was proposed as Equation (6). The proposed estimation equation confirmed that it is possible to estimate the compressive strength of concrete according to its age using nondestructive testing methods. In particular, the proposed estimation equation is expected to be helpful in preventing problems caused by formwork removal by providing construction sites with valuable information at early ages of the concrete.

Author Contributions: S.H., S.Y., C.L., and J.K. conceived and performed the experiments and analyzed the data and wrote the paper. Y.L. and S.K. supervised this project as a research director. All authors have read and agreed to the published version of the manuscript.

Funding: National Research Foundation of Korea (NRF) funded by the Ministry of Education. Award Number: NRF-2017R1A2B2009743 (Recipient: Yongtaeg Lee, Ph.D).

Acknowledgments: This research was supported by Basic Science Research Program through the National Research Foundation of Korea (NRF) funded by the Ministry of Education (NRF-2017R1A2B2009743).

Conflicts of Interest: The authors declare no conflict of interest.

\section{References}

1. ACI 228.2R. Nondestructive Test Methods for Evaluation of Concrete in Structures; American Concrete Institute: Farmington Hills, MI, USA, 2013.

2. ASTM C 597. Standard Test Method for Pulse Velocity through Concrete; American Society for Testing and Materials: West Conshohocken, PA, USA, 2016.

3. ASTM C 1383. Standard Test Method for Measuring the P-wave Speed and the Thickness of Concrete Plates Using the Impact Echo Method; American Society for Testing and Materials: West Conshohocken, PA, USA, 2015.

4. Azari, H.; Nazarian, S.; Yuan, D. Assessing sensitivity of impact echo and ultrasonic surface wave methods for nondestructive evaluation of concrete structures. Constr. Build. Mater. 2014, 71, 384-391. [CrossRef]

5. Sabbag, N.; Uyanık, O. Prediction of reinforced concrete strength by ultrasonic velocities. J. Appl. Geophys. 2017, 141, 13-23. [CrossRef]

6. Ghosh, R.; Sagar, S.P.; Kumar, A.; Gupta, S.K.; Kumar, S. Estimation of geopolymer concrete strength from ultrasonic pulse velocity using high power pulser. J. Build. Eng. 2018, 16, 39-44. [CrossRef]

7. Naderpour, H.; Rafiean, A.H.; Fakharian, P. Compressive strength prediction of environmentally friendly concrete using artificial neural networks. J. Build. Eng. 2016, 16, 213-219. [CrossRef]

8. Pal, P. Dynamic Poisson's ratio modulus of elasticity of pozzolana Portland cement concrete. Int. J. Eng. Technol. Innov. 2019, 9, 131-144.

9. Panedpojaman, P.; Tonnayopas, D. Rebound hammer test to estimate compressive strength of heat exposed concrete. Constr. Build. Mater. 2018, 172, 387-395. [CrossRef]

10. Hong, S.U.; Lee, Y.T.; Kim, S.H.; Lee, C.S. Estimation of Thickness of Concrete Structures using the Impact Echo Method and Ultrasonic Pulse Velocity Method. Archit. Res. 2016, 18, 179-184. [CrossRef] 
11. Hong, S.U.; Cho, Y.S. A Study on the Damage Detection of Concrete Structures using Impact Echo Method based on Stress Waves. J. Archit. Inst. Korea 2006, 22, 11-18.

12. Bogas, J.A.; Gomes, M.G.; Gomes, A. Compressive strength evaluation of structural lightweight concrete by non-destructive ultrasonic pulse velocity method. Ultrasonics 2013, 53, 962-972. [CrossRef] [PubMed]

13. Furuichi, N. Fundamental uncertainty analysis of flow rate measurement using the ultrasonic Doppler velocity profile method. Flow Meas. Instrum. 2013, 33, 202-211. [CrossRef]

14. Roh, Y.S. Corrosion Level Measurement Technique for RC Wall Reinforcement Using Non-Destructive Test Methods. J. Korean Soc. Nondestruct. Test. 2011, 31, 24-31.

15. Baek, I.K.; Cho, S.H.; Chung, L. Non-destructive Measurement Method of Reinforcement Corrosion Level by Infrared Thermography Data. J. Archit. Inst. Korea 2005, 21, 3-10.

16. Naderpour, H.; Rafiean, A.H.; Fakharian, P. Analytical and genetic programming model of compressive strength of eco concretes by NDT according to curing temperature. Constr. Build. Mater. 2017, 144, 195-206.

17. Saint-Pierre, F.; Philibert, A.; Giroux, B.; Rivard, P. Concrete Quality Designation based on Ultrasonic Pulse Velocity. Constr. Build. Mater. 2016, 125, 1022-1027. [CrossRef]

(C) 2020 by the authors. Licensee MDPI, Basel, Switzerland. This article is an open access article distributed under the terms and conditions of the Creative Commons Attribution (CC BY) license (http://creativecommons.org/licenses/by/4.0/). 